\title{
5-HT2C receptor blockade reverses SSRI-associated basal ganglia dysfunction and potentiates therapeutic efficacy
}

\author{
Elena Y. Demireva ${ }^{1,2}$ - Deepika Suri ${ }^{1}$ Emanuela Morelli ${ }^{1}$ - Darshini Mahadevia ${ }^{1} \cdot$ Nao Chuhma ${ }^{1,3}$. \\ Catia M. Teixeira ${ }^{1,2}$ - Annette Ziolkowski ${ }^{1,2} \cdot$ Marc Hersh $^{1} \cdot$ James Fifer $^{1} \cdot$ Sneha Bagchi ${ }^{1}$ - Alexei Chemiakine ${ }^{1}$. \\ Holly Moore ${ }^{1,4} \cdot$ Jay A. Gingrich ${ }^{1,2} \cdot$ Peter Balsam ${ }^{1,2} \cdot$ Stephen Rayport ${ }^{1,3} \cdot$ Mark S. Ansorge $^{1,2}$
}

Received: 30 November 2016 / Revised: 13 July 2018 / Accepted: 24 July 2018 / Published online: 17 August 2018

(c) Springer Nature Limited 2018

\begin{abstract}
Serotonin (5-HT) selective reuptake inhibitors (SSRIs) are widely used in the treatment of depression and anxiety disorders, but responsiveness is uncertain and side effects often lead to discontinuation. Side effect profiles suggest that SSRIs reduce dopaminergic (DAergic) activity, but specific mechanistic insight is missing. Here we show in mice that SSRIs impair motor function by acting on 5-HT2C receptors in the substantia nigra pars reticulata $(\mathrm{SNr})$, which in turn inhibits nigra pars compacta (SNc) DAergic neurons. SSRI-induced motor deficits can be reversed by systemic or SNr-localized 5-HT2C receptor antagonism. SSRIs induce SNr hyperactivity and SNc hypoactivity that can also be reversed by systemic 5-HT2C receptor antagonism. Optogenetic inhibition of SNc DAergic neurons mimics the motor deficits due to chronic SSRI treatment, whereas local SNr 5-HT2C receptor antagonism or optogenetic activation of SNc DAergic neurons reverse SSRIinduced motor deficits. Lastly, we find that 5-HT2C receptor antagonism potentiates the antidepressant and anxiolytic effects of SSRIs. Together our findings demonstrate opposing roles for 5-HT2C receptors in the effects of SSRIs on motor function and affective behavior, highlighting the potential benefits of 5-HT2C receptor antagonists for both reduction of motor side effects of SSRIs and augmentation of therapeutic antidepressant and anxiolytic effects.
\end{abstract}

\section{Introduction}

5-HT and DA neurotransmission are highly interconnected in both normal brain function and disease. Their

These authors contributed equally: Elena Y. Demireva and Deepika Suri.

Electronic supplementary material The online version of this article (https://doi.org/10.1038/s41380-018-0227-x) contains supplementary material, which is available to authorized users.

Mark S. Ansorge

ma2362@cumc.columbia.edu

1 Department of Psychiatry, Columbia University, New York, NY 10032, USA

2 Department of Developmental Neuroscience, New York State Psychiatric Institute, New York, NY 10032, USA

3 Division of Molecular Therapeutics, New York State Psychiatric Institute, New York, NY 10032, USA

4 Division of Systems Neuroscience, New York State Psychiatric Institute, New York, NY 10032, USA dysregulation influences psychiatric states, and most neuropsychiatric medications act in these two systems. How the transmitter systems influence each other is of key importance for understanding normal brain function, psychopathology, and pharmacotherapy. SSRIs that block the 5-HT transporter (5-HTT) are currently the most widely prescribed psychiatric drugs. They are prescribed not only as a first-line treatment for depressive disorders, but also for many other psychiatric disorders, including bipolar, obsessive-compulsive, panic and generalized anxiety disorder. Despite their widespread use, SSRIs face both efficacy and side-effect challenges [1]. One hypothesis is that their therapeutic shortcomings arise from 5-HTergic modulation of the DA system [2]. Indeed, several side effects of SSRIs such as anhedonia, apathy, emotional blunting, reduced libido, akathisia, and extrapyramidal motor symptoms (EPS) point to DAergic hypofunction in the behavioral and emotional effects of SSRIs [3-8]. Animal studies support this idea, with several studies demonstrating inhibitory effects of pharmacologically increased extracellular 5-HT on midbrain DAergic function [9, 10]. In mice, and occasionally in predisposed patients, 
such blunted DAergic function can induce parkinsonism [2, 11].

To improve 5-HTT-based pharmacotherapy, one approach has been to compensate for DAergic dysregulation by directly targeting the DA system with compounds such as bupropion or amphetamines [12]. But such augmentation strategies, which broadly impact DA signaling, have had little success and can themselves have adverse effects. A more targeted approach requires therapies that directly address the mechanism by which SSRI-induced increase in 5-HTergic tone leads to DA hypofunction. To that end, it is important to identify the 5-HT receptors whose activation is responsible for mediating the inhibitory effects on DA signaling. Among the fourteen 5-HT receptors, one promising candidate is the 5-HT2C receptor, which is expressed by $\mathrm{SNr}$ and VTA GABAergic neurons, and its antagonism reverses acute effects of SSRIs on VTA DAergic activity [13-15]. Furthermore, 5-HT2C receptor agonism reduces incentive motivation [16, 17], while antagonism increases motivation [18-20], with a hypothesized mechanism centered on 5-HT acting at 5-HT2C receptors to reduce motivation by suppressing mesolimbic DAergic activity [20].

Here we investigate the role of 5-HT2C receptors in mediating the effects of 5-HTT blockade on basal ganglia (BG) function and emotional behaviors. We find that 5HT2C receptor activation plays a selective and pivotal role in the suppression of the DAergic nigrostriatal pathway associated with impaired motor function during SSRI treatment. We directly assess the roles of $\mathrm{SNr}$ 5-HT2C receptors and SNc DAergic activity in regulating motor function, and we investigate the interaction between 5-HTT blockade and 5-HT2C receptor antagonism in anxiety- and depression-related behavior. Our findings provide mechanistic insight into 5-HTergic modulation of DAergic function and highlight 5-HT2C receptor antagonism for augmentation therapy to improve antidepressant efficacy of SSRI treatment and reduce basal ganglia mediated side-effects.

\section{Materials and methods}

\section{Transgenic mice}

Mice heterozygous for the 5 -htt mutation $\left(5-h t t+/-, 10^{\text {th }}\right.$ $12^{\text {th }}$ generation $\left.129 \mathrm{~S} 6 / \mathrm{SvEv}\right)$ were crossed to produce $5-\mathrm{htt}$ $+/+$, 5-htt+/-, and 5-htt-/- offspring see [21]. Independent groups of male subjects weighing 25-45 g were experimentally tested at ages 2-13 months. Heterozygous crossings were also used to generate experimental groups of $+/+$ and -/- mice for htrla [22], htrlb [23], htr2a [24], and htr4 [25]. Offspring resulting from these crosses were experimentally tested at approximately 5 months of age and weighed 25-35 g. All subjects were genotyped by PCR of genomic DNA isolated from tissue samples harvested at 18-21 days of age.

\section{Animal husbandry}

Animals were housed in groups of five per cage and provided with food and water ad libitum (except as noted). Animals were maintained on a $12 \mathrm{~h}$ light/dark cycle (8:00 A. M./8:00 P.M.) Animal testing was conducted during the light phase of the light cycle. Animal testing was conducted in accordance with National Institutes of Health (NIH) Laboratory Animal Care and Welfare guidelines and approved by the Institutional Animal Care and Use Committees of Columbia University and NYS Psychiatric Institute.

\section{Animal use}

The numbers of mice used were based on a power analysis assuming a $30 \%$ mean effect size of manipulations and an acceptable probability level of 0.05 . Mice were randomized when allocated to treatment groups balancing for litter, sex, and genotype. Investigators were blinded to group allocations during testing and scoring.

\section{Drugs}

Fluoxetine (FLX; ANAWA Trading SA, Wangen, Switzerland), was dissolved in $0.9 \% \mathrm{NaCl}$ or drinking water to achieve $2.5,5$, or $10 \mathrm{mg} / \mathrm{kg}$ when administered intraperitoneally (i.p.) or through the drinking water (see supplementary data). The 5-HT2C receptor inverse agonist SB206553 (Tocris, Ellisville, MO), the 5-HT2C receptor antagonist SB242084 (Tocris), the 5-HT2C receptor agonist WAY161503 (Tocris), and the 5-HT3 receptor antagonist ondansetron (Tocris) were dissolved by sonication in $0.9 \%$ $\mathrm{NaCl}$ to achieve concentrations between 0.1 and $5 \mathrm{mg} / \mathrm{kg}$ when administered i.p. For local infusions, SB242084 was first dissolved in DMSO to $10 \mathrm{mg} / \mathrm{ml}$, and then diluted at $1: 100$ in saline to obtain a final concentration of $0.1 \mathrm{mg} / \mathrm{ml}$.

\section{In vivo electrophysiology}

Extracellular recording microelectrodes $(2.0 \mathrm{~mm}$ OD borosilicate glass capillary tubing, $\sim 1 \mu \mathrm{m}$ tip diameter, impedance 5-10 MOhms) were filled with $2 \mathrm{M} \mathrm{NaCl}$ containing $2 \%$ pontamine sky blue dye. The electrode signal was amplified, filtered and discriminated from noise. Mice were anesthetized with isoflurane $1-2 \%$ in oxygen via a standard veterinary inhalation anesthesia apparatus. Body temperature was monitored by a rectal probe and maintained between $36-37^{\circ} \mathrm{C}$ using a water circulation pad placed 
under a clean gauze pad. A hole was drilled through the skull overlying the brain structures of interest, and the dura was then punctured. A glass electrode was lowered with a hydraulic microdrive into the $\mathrm{SNc}$ and $\mathrm{SNr}$ at coordinates: anterior/posterior (AP) $+4.0 \mathrm{~mm}$, medial/lateral (ML) 1.1$2.3 \mathrm{~mm}$ from Bregma, and dorsal/ventral (DV) $3.5-5.5 \mathrm{~mm}$ from brain surface. DAergic and non-DAergic neurons were identified using established electrophysiological criteria [26, 27] and once isolated, spontaneous activity was recorded for 2-3 min. The SNc and SNr were systematically investigated by recording from 4-6 tracks within a region per mouse. Three parameters of activity were sampled: (1) the number of spontaneously active DAergic and non-DAergic neurons recorded per electrode track (i.e., population activity), (2) basal firing rate (average number of spikes/second per cell) and (3) bursting activity. The start of a burst was defined by the occurrence of two spikes with an interspike interval $<80$ $\mathrm{ms}$, and its termination by the occurrence of an interspike interval $>160 \mathrm{~ms}$. Data were continuously digitalized by a Neurocorder DR-890 A/D converter (Cygnus Technologies, Delaware Water Gap, PA) and stored on a hard drive using a data acquisition board (Microstar Labs, Bellevue, WA) interfaced with a computer. Analysis was performed with custom-designed software (NeuroscopeC).

\section{Optogenetic photo-tagging}

Accuracy of electrophysiological criteria for the identification of DAergic neurons in vivo was verified using optogenetic photo-tagging. Specifically, we recorded from DAT-ires-Cre mice crossed with the Ai32 line, using glass electrodes coupled to a fiberoptic cable to record lighttriggered spike elicitation. SNc DA-like cells were first isolated using electrophysiological criteria and subjected to baseline recording for 2-3 mins. Thereafter, the cells were stimulated using blue light pulses $(473 \mathrm{~nm}, 5$ pulses at $5 \mathrm{~Hz}$, $10 \mathrm{~ms}$ pulse duration, $8 \mathrm{~mW}$, five repeats). Latency of spike post stimulation, fidelity of response, and waveforms of spikes during baseline recordings and in response to stimulation, were assessed.

\section{Slice electrophysiology}

To test for direct connectivity between SNr GABAergic neurons and SNc DAergic neurons, AAV5-ef1 $\alpha$-DIOhChR2(H134R)-eYFP virus was injected bilaterally into the $\mathrm{SNr}$ of P50-55 vesicular GABA transporter Cre mice (VGAT-Ires-Cre) (SNr co-ordinates: AP: +3.3 mm, ML: $+/-1.3$ and $1.6 \mathrm{~mm}, \mathrm{DV}:-4.4 \mathrm{~mm}, 300 \mathrm{nl}$ per injection site) at a rate of $0.2 \mu \mathrm{l} / \mathrm{min}$ using Nanoject II (Drummond Scientific Company). The injection capillary was left in place for $15 \mathrm{~min}$ after the infusion at each injection site and mice were returned to their home cages post-surgery. The virus was allowed to express for 3 weeks, after which the animals were euthanized, and $300 \mu \mathrm{m}$ horizontal brains slices containing ventral midbrain were sliced using vibratome (VT1200S, Leica). Electrophysiological recordings were performed in regular ACSF (in mM: $125 \mathrm{NaCl}, 2.5$ $\mathrm{KCl}, 25 \mathrm{NaHCO} 3,1.25 \mathrm{NaH} 2 \mathrm{PO} 4,2 \mathrm{CaCl} 2,1 \mathrm{MgCl} 2$ and 25 glucose, $\mathrm{pH}$ 7.4) saturated with $95 \% \mathrm{O}_{2}, 5 \% \mathrm{CO}_{2}$ at 31-33 ${ }^{\circ} \mathrm{C}$. Patch pipettes contained the following solution (in $\mathrm{mM}$ ): $135 \mathrm{Cs}+-$ methane sulfonate (MeSO4), $5 \mathrm{KCl}$, $2 \mathrm{MgCl} 2,0.1 \mathrm{CaCl} 2,10$ HEPES, 1 EGTA, 2 ATP and 0.1 GTP, pH 7.25, supplemented with QX314 (lidocaine Nethyl bromide, Sigma-Aldrich) $5 \mathrm{mM}$ for blocking unclamped action potentials and 0.5-1 mM Alexa Fluor 594 (ThermoFisher Scientific) for post-recording identification. Pipette resistance was 3-7 M 2 . Neurons were visualized with an upright Olympus microscope (BX61WI). SNc neurons were visually identified as large spindle-shaped neurons densely packed and located lateral of the lateral lemniscus, and confirmed by post-recording immunostaining, while ChR2-EYFP expression was confirmed by field illumination with a $470 \mathrm{~nm}$ LED (DC4100, Thorlabs). Voltage clamp recording was performed with Axopatch 200B amplifier (Molecular Devices), holding at $0 \mathrm{mV}$. Synaptic responses were evoked with $5 \mathrm{msec}$ field illumination with the high-power LED, delivered either as a single pulse at $0.1 \mathrm{~Hz}$, or in a train of ten pulses at $10 \mathrm{~Hz}$, at $30 \mathrm{~s}$ intervals. For confirmation of $\mathrm{GABA}_{\mathrm{A}}$ mediation of synaptic currents, the $\mathrm{GABA}_{\mathrm{A}}$ antagonist SR95531 (gabazine, $10 \mu \mathrm{M}$ ) was delivered by perfusion. Data were filtered at $5 \mathrm{kHz}$ using a 4-pole Bessel filter, digitized at $5 \mathrm{kHz}$ (Digidata 1550A, Molecular Devices) and recorded using pClamp 10 software (Molecular Devices). Data were analyzed with Axograph X (Axograph Science). IPSC amplitude was measured as peak after stimulation in averaged traces made from ten consecutive raw traces. IPSC onset was determined as the interval from the onset of illumination to $5 \%$ of the IPSC peak; rise time of the IPSC was determined as the interval from 10 to $90 \%$ of the IPSC peak. Data are shown as mean \pm S.E.M.

\section{Post-recording immunostaining}

Recorded slices were fixed in 4\% PFA and washed in $0.1 \mathrm{M}$ PBS. Non-specific binding was blocked with $10 \%$ normal horse serum in $0.1 \mathrm{M}$ PBS Triton X-100 for $2 \mathrm{~h}$. Sections were incubated with anti-TH antibody (1:1000; Rabbit anti TH, EMD Millipore AB152) in 0.02\% PBS-T and $2 \%$ horse serum for $48 \mathrm{~h}$ at $4{ }^{\circ} \mathrm{C}$ on a shaker. Sections were then washed with PBS and incubated with secondary antibody (1:300, Donkey anti Rabbit Alexa Fluor 488 ) for $2 \mathrm{~h}$ in $0.02 \%$ PBS-T at room temperature. Recorded cells were visualized with direct fluorescence of Alexa Fluor 594. 


\section{Local infusion}

Under anesthesia and using standard stereotaxic procedures, stainless-steel guide cannulas (22 gauge; PlasticOne) were implanted into the SNr (AP: $-3.5 \mathrm{~mm}, \mathrm{~L}:+/-1.6 \mathrm{~mm}$, DV: $-4.6 \mathrm{~mm}$ ) or dorsal striatum (AP: $+1 \mathrm{~mm}, \mathrm{~L}:+/-1.6 \mathrm{~mm}$, DV: $-2.8 \mathrm{~mm})$. Mice were allowed to recover for at least 1 week after surgery, $15 \mathrm{~min}$ before behavioral testing, mice received $1 \mu \mathrm{l}$ infusions of either drug $(0.1 \mathrm{mg} / \mathrm{ml}$ of SB242084 in 1\% DMSO) or vehicle (1\% DMSO in saline) at a rate of $0.2 \mu \mathrm{l} / \mathrm{min}$. The injection cannula (28 gauge; Plastics One) was left in place for 2 min after the infusion, after which mice were returned to their home cages before testing.

\section{Optogenetic manipulation of SNc dopaminergic neurons}

In order to selectively express channelrhodopsin2 (ChR2) or Archaerhodopsin (Arch 2.0) in DA neurons, we crossed a dopamine transporter Cre-driver-line (DAT-IRES-Cre) with a ROSA26-floxSTOP-ChR2-eYFP line (Ai32) or a ROSA26- floxSTOP-Arch-GFP line (Ai35), respectively [28]. Under isofluorane anesthesia, optical fiber ferrules (Ceramic ferrules OD $1.2 \mathrm{~mm}$ Precision fiber products; Optical fiber OD $0.2 \mathrm{~mm}$, Thorlabs, Newton, NJ, USA), were implanted over the $\mathrm{SNc}$ (Stimulation experiment $\mathrm{SNc}$ coordinates: AP: $-3.5 \mathrm{~mm}$; ML: $+/-1.6 \mathrm{~mm}$; DV: -4.4 $\mathrm{mm}$; inhibition experiment SNc coordinates: AP: $-3.5 \mathrm{~mm}$; ML: $+/-1.3 \mathrm{~mm}$; DV: $-4.4 \mathrm{~mm}$ ). After recovery, mice were trained on a rotarod apparatus (see behavioral testing). For the optogenetic stimulation experiment, trained mice received chronic fluoxetine treatment for a period of at least two weeks prior to testing. Testing was performed at 20 and $30 \mathrm{rpm}$ in constant speed mode. For stimulation phases, blue light pulses $(473 \mathrm{~nm}, 20 \mathrm{~Hz}, 10 \mathrm{~ms}$ pulse duration, $8 \mathrm{~mW}$ ) were delivered bilaterally, whereas for inhibition phases, green light pulses ( $532 \mathrm{~nm}$, continuous, $8 \mathrm{~mW}$ ) were delivered. Testing took place over two consecutive days, counterbalancing the blue and green light phase order by genotype. After behavioral tests were completed, mice were euthanized, and genotypes and fiber placements were confirmed.

\section{Behavioral testing}

The open field test was performed as previously described [21]. In short, motor activity was quantified in Plexiglas activity chambers (Model ENV-520; Med Associates, Georgia, VT) $(43.2 \times 43.2 \times 30.5 \mathrm{~cm}$, length, width, height $)$ equipped with infrared beams located $1.5 \mathrm{~cm}$ above the chamber floor and spaced $2.5 \mathrm{~cm}$ apart to detect horizontal activity. Vertical activity was detected using another set of infrared beams $6 \mathrm{~cm}$ above the chamber floor and spaced $2.5 \mathrm{~cm}$ apart. Locomotor activity was measured as total ambulatory distance and total ambulatory time.

The Rotarod apparatus (Accelerating Model, Ugo Basile, Biological Research Apparatus, Varese, Italy) was used to measure motor coordination and balance as previously described [2]. In short, mice were placed individually on the rotating rotarod system and trained for six consecutive days, first in accelerating speed mode at $0-20,0-30$, and $0-40 \mathrm{rpm}$ and then in constant speed mode at 20,30, and $40 \mathrm{rpm}$. Mice received three training trials per day. Testing was performed in constant speed mode. Overall rotarod performance was expressed as latency to fall.

For novelty-suppressed feeding, testing was performed as previously described [29]. Mice were food deprived for $24 \mathrm{~h}$ prior to testing. Weights were recorded before and after food deprivation. At the time of testing, a food pellet was affixed on top of a white filter paper disc (13 cm diameter) placed in the middle of a open arena (box of $50 \times 50 \times 20 \mathrm{~cm}$ ) covered with two in of fresh bedding. Each mouse was placed in one corner and allowed to explore for a maximum of $15 \mathrm{~min}$. The time to begin eating was recorded. Immediately after an eating event, the mouse was transferred to its home cage and allowed to free-feed for $5 \mathrm{~min}$. The amount of home cage food consumption was recorded.

For the forced swim test, we adapted a protocol to test the effect of chronic treatments [30]. Mice were placed in 31 beakers with $2200 \mathrm{ml}$ of water at $25^{\circ} \mathrm{C}$, and allowed to swim for $6 \mathrm{~min}$ sessions, which were recorded using VideoTrak software. Videos were scored for periods of active mobility duration and immobility. Mice were trained with a single 6 min session per day, for five consecutive days, off-drug. Testing began 30 days after chronic treatment with either fluoxetine or vehicle. Acute injections of SB242084 or vehicle were administered on test days, $30 \mathrm{~min}$ before the start of the test. SB242084 was administered at $0.2 \mathrm{mg} / \mathrm{kg}, 0.5 \mathrm{mg} / \mathrm{kg}$, and $1 \mathrm{mg} / \mathrm{kg}$ on six separate test days, using a crossover design. Each testing day was separated by a minimum of seven days.

For Learned Helplessness $(L H)$, the inescapable shock (IS) and shuttle box shock escape (SE) procedures were conducted as previously described [31] in a two-chamber shuttle box (model ENV 010MD; Med Associates, St. Albans, VT) placed within a sound-attenuated cubicle. The apparatus was equipped with a grid floor made of a stainless steel, connected to a shock generator. A scrambled shock generator (model ENV 414S, Med Associates) created varying electrical potential differences between grid bars preventing an animal from avoiding shock. The LH protocol was modified to accommodate chronic treatment [32], as follows. Mice were exposed to a single IS session per day for 3 consecutive days. Each session consisted of 140 trials, 
with a variable inter trial interval (ITI) of $15 \mathrm{~s}$ (range, 1-30 s), variable shock duration of $3 \mathrm{~s}$ (range 1-5 s), and increasing shock intensities of $0.3,0.4$, and $0.5 \mathrm{~mA}$ to prevent habituation during the trial. After 3 days of training mice were administered drinking water that was either fluoxetine-treated $(100 \mathrm{mg} / \mathrm{l})$ or untreated, for the remainder of the experiment. Drinking water was kept in dark bottles and was replaced every 3 days. Mice received a single IS reminder session, 10 days after the start of treatment, consisting of 10 trials with an ITI of $60 \mathrm{~s}$ (range, 30-88 s), shock duration of $3 \mathrm{~s}$ (range $1-5 \mathrm{~s}$ ), and current intensity of $0.4 \mathrm{~mA}$. After 22 days from the start of the experiment, mice were tested in the SE paradigm to assess the degree of learned helplessness in the same shuttle boxes as the IS exposure. SB242084 $(1 \mathrm{mg} / \mathrm{kg})$ was administered acutely via i.p. injection $20 \mathrm{~min}$ prior to testing. Mice were placed in the same shuttle boxes used for IS exposure; after a 3 min habituation period, 30 escape trials were performed with an ITI of $30 \mathrm{~s}$ and current intensity of $0.4 \mathrm{~mA}$ - at the start of each trial the gate separating the two chambers was lifted $5 \mathrm{~s}$ before shock onset. As the shocks were delivered mice could escape into the opposite chamber terminating the foot shock and the trial (maximum trial duration was set at $15 \mathrm{~s}$ ). Escape latencies were computed as the time from shock onset to the time of escape or end of trial.

\section{Statistical analysis}

Statistical analysis was performed using StatView 5.0 software (SAS Institute, Cary, NC), Excel (Microsoft, Redmond, WA), and Prism (GraphPad Software, La Jolla, CA). Sample sizes were chosen. Data were analyzed using Student's $t$ test, one-way or two-way ANOVA. The criterion for significance for all analyses was $p<0.05$. Post hoc comparisons were conducted using the Student-NewmanKeuls test for between-subject designs and Fisher's LSD for within-subject designs. Results from data analyses are expressed as mean \pm SEM. Plot and statistical analysis of slice electrophysiology data were done by $\mathrm{R}$ version 3.3.3 with base and ggplot2 packages. Independent sample $t$ test without equal variance assumption (Welch's $t$-test) for comparison between two stimulus frequencies.

\section{Results}

\section{Acute 5-HT2C receptor antagonism reverses motor deficits induced by chronic 5-HTT blockade}

To study the mechanism underlying the consequences of increased 5-HT signaling on BG dysfunction, we first sought to identify critical 5-HT receptors involved in this process. Using genetic and pharmacological tools, we investigated the role of 5-HT1A, 5-HT1B, 5-HT2A,
5-HT2C, 5-HT3 and 5-HT4 receptors (all of which are expressed in the $\mathrm{BG}$ ) in mediating the effects of enhanced 5-HT signaling on BG dysfunction. To achieve this, we used an unbiased screening approach, along with evaluation of mouse behavior in the rotarod test as readout of BGdependent motor performance. We treated htrla-, htrlb-, $h t r 2 a-$, and htr4-deficient mice and their respective $w t$ controls with the SSRI fluoxetine (FLX) or vehicle (VEH) for at least 3 weeks, after which each genotype $\mathrm{x}$ treatment group was tested in the rotarod assay. We found a main effect of treatment, but did not find a main effect of genotype or a genotype by treatment interaction on motor dysfunction in this test (Figure S1). These findings demonstrate that htrla-, htrlb-, htr2a-, and htr4-mutant mice are sensitive to the effects of FLX on motor function, and therefore likely rule out a role for these receptors in BG-mediated motor dysfunction.

To investigate the potential contribution of increased 5 -HT2C or 5-HT3 receptor signaling on the effects of chronic 5-HTT blockade on motor behavior, we next used a pharmacological approach to assess whether FLX-induced motor deficits can be reversed by blocking 5-HT2C or 5-HT3 receptors. To test the role of 5-HT2C receptor activation in chronic FLX-induced motor dysfunction, we administered the 5-HT2C receptor antagonist SB242084 $(0.2-5 \mathrm{mg} / \mathrm{kg}$, i.p.) acutely prior to rotarod testing of either FLX or VEH-treated wild-type mice. We found a main effect of FLX, a main effect of SB242084, and a FLX by SB242084 interaction at $20 \mathrm{rpm} \quad\left(F_{1,38}=79.209, \quad p<\right.$ $0.0001, F_{3,114}=18.886, p<0.0001$, and $F_{3,114}=10.787, p$ $<0.0001$, respectively $)$ and $30 \mathrm{rpm}\left(F_{1,38}=41.106, p<\right.$ $0.0001, \quad F_{3,114}=33.864, p<0.0001$, and $F_{3,114}=3.764$, $p=0.0128$, respectively) (Fig. 1a). Posthoc analyses revealed that acute SB242084 treatment reversed the motor deficit elicited by chronic FLX treatment in a dosedependent manner (Fig. 1a). Lastly, to test the role of 5-HT3 receptor activation in FLX-induced rotarod deficits we used acute pre-treatment with the 5-HT3 receptor antagonist ondansetron $(0.1-1 \mathrm{mg} / \mathrm{kg}$, i.p.) and detected a main effect of FLX, but no effect of ondansetron, and no FLX by ondansetron interaction at $20 \mathrm{rpm}\left(F_{1,24}=9.888\right.$, $p=0.0044, \quad F_{2,48}=2.404, p=0.1012$, and $F_{2,48}=0.02$, $p=0.9798$, respectively $)$ or $30 \mathrm{rpm}\left(F_{1,24}=9.784, p=\right.$ $0.0046, F_{2,48}=0.417, p=0.6631$, and $F_{2,48}=0.195, p=$ 0.8236 , respectively) (Figure S2).

In sum, these data indicate that out of all of the tested receptors (5-HT1A, 5-TH1B, 5HT2A, 5-HT2C, 5-HT3 and 5-HT4), only 5-HT2C receptor signaling is involved in mediating motor deficits induced by chronic SSRI treatment. We thus infer that chronic FLX leads to indirect stimulation of 5-HT2C receptors to impair motor function. To test this conclusion directly, we assessed the effect of WAY161503 (a full agonist of 5-HT2C receptors, 
a 20 RPM, FLX by SB242084 interaction: ***

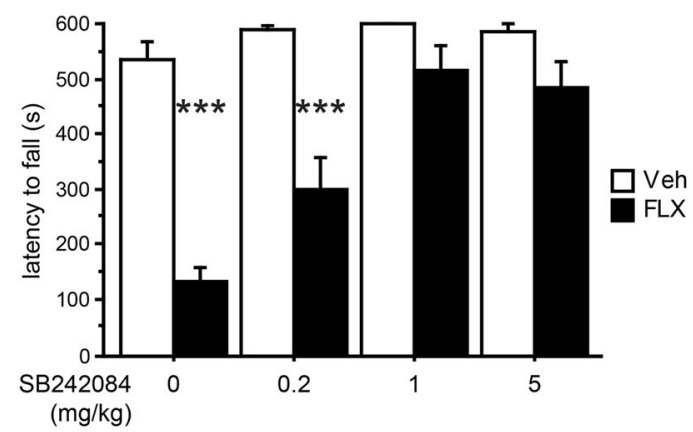

b 20 RPM, WAY161503 by SB242084 interaction: *

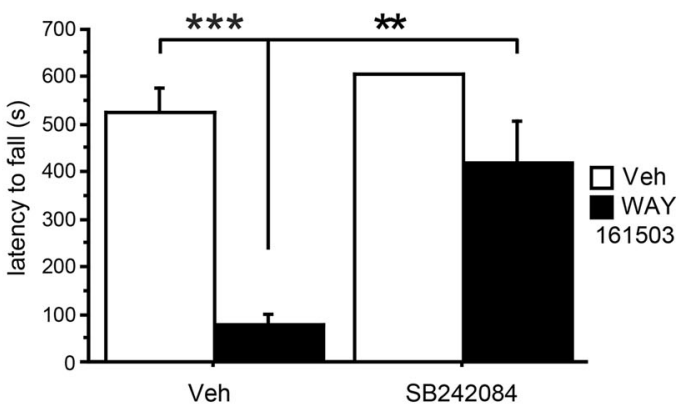

C 20 RPM, main effect of VEH/SB242084:*** main effect of genotype: *

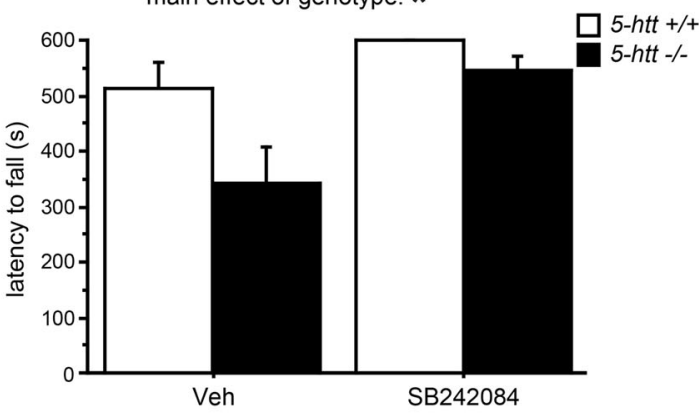

d 20 RPM, genotype by SB206553 interaction: *

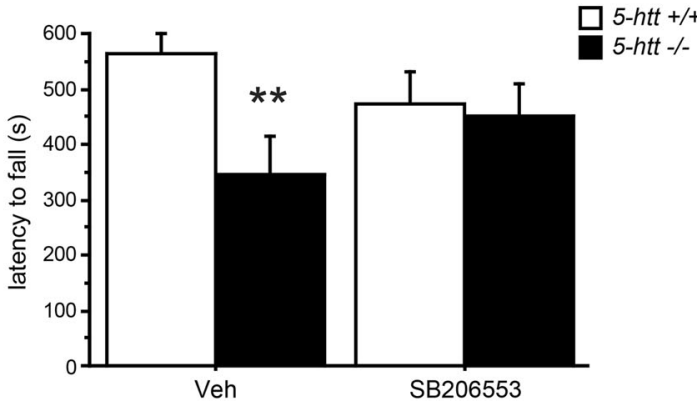

Fig. 1 5-HT2C receptor antagonism reverses motor deficits elicited by chronic 5-HTT blockade. Motor behavior was evaluated using rotarod test. a Acute SB242084 treatment (selective 5-HT2C receptor antagonist, $0.2-5 \mathrm{mg} / \mathrm{kg}$, i.p.) reversed chronic FLX-induced reductions in the latency to fall in a dose-dependent fashion $(n=20$ mice per group). b Acute WAY161503 treatment (selective 5-HT2C receptor agonist, $3 \mathrm{mg} / \mathrm{kg}$, i.p.) mimicked chronic FLX-induced reductions in the latency to fall, which was reversed by acute
30 RPM, FLX by SB242084 interaction: *

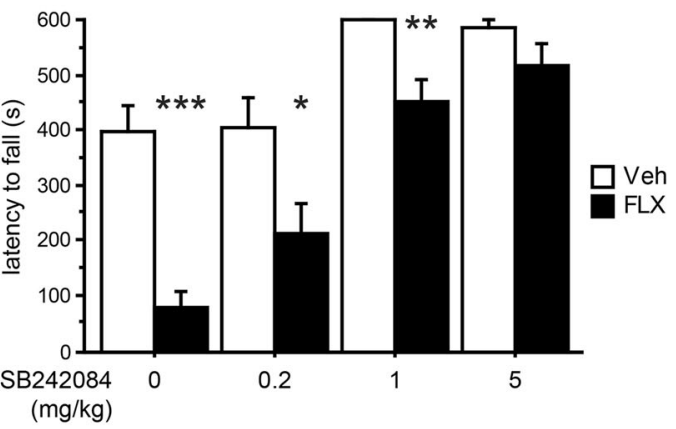

30 RPM, main effect of VEH/WAY161503: ***

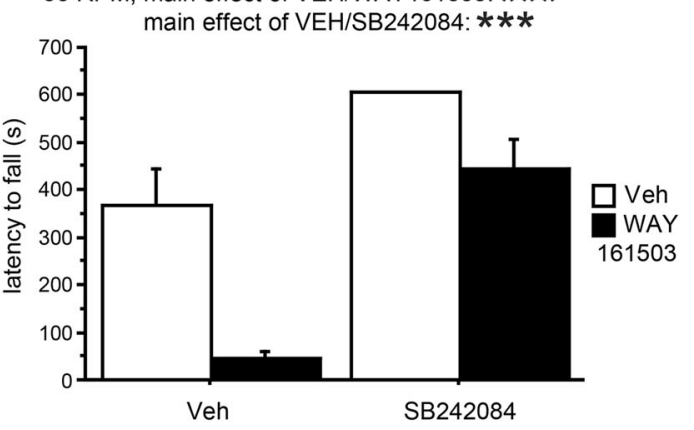

30 RPM, main effect of VEH/SB242084:*** main effect of genotype: $* * *$

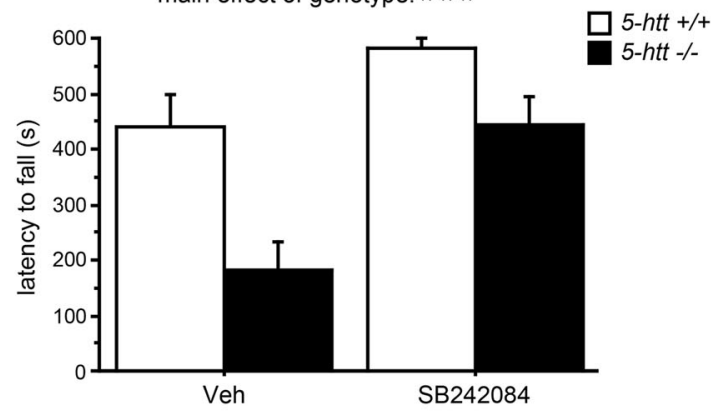

30 RPM, main effect of VEH/SB206553:*** main effect of genotype: *

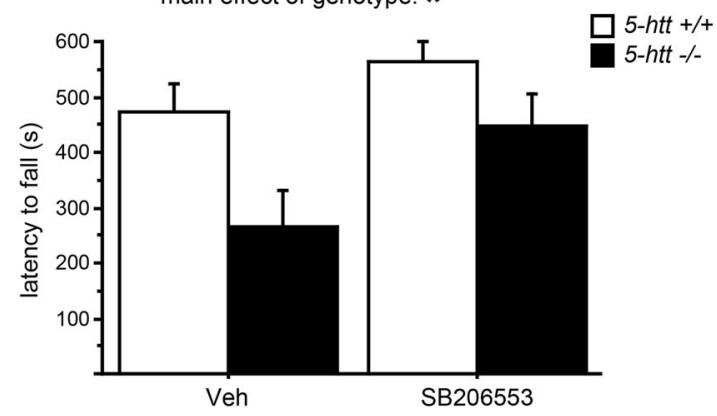

SB242084 treatment (selective 5-HT2C receptor antagonist, $5 \mathrm{mg} / \mathrm{kg}$, i.p.) ( $n=9-10$ mice per group). c Acute SB242084 treatment (5 mg/tkg, i.p.) reversed 5-htt genetic ablation-induced reductions in the latency to fall ( $n=14-15$ mice per group). d Acute SB206553 treatment (5-HT2C receptor inverse agonist, $10 \mathrm{mg} / \mathrm{kg}$, i.p.) reversed 5 - $h t t$ ablation-induced reductions in the latency to fall $(n=13-15$ mice per group). $(* p<0.05 ; * * p<0.01 ; * * * p<0.001)$ 
$3 \mathrm{mg} / \mathrm{kg}$, i.p.) alone and in combination with SB242084 $(5 \mathrm{mg} / \mathrm{kg}$, i.p.) in the rotarod test. In support of our conclusion, we found an interaction of WAY161503 and SB242084 at $20 \mathrm{rpm}\left(F_{1,17}=7.262, p=0.0153\right)$ and main effects of treatment at $30 \mathrm{rpm}$ (WAY161503: $F_{1,17}=$ $22.581, \quad p=0.0002 ; \quad$ SB242084: $\quad F_{1,17}=43.015, \quad p<$ 0.0001 ), with WAY161503 producing motor-impairing effects that were reversed by SB242084 (Fig. 1b). Therefore, acute exogenous stimulation of 5-HT2C receptors mimics the effect of chronic 5-HT level elevation.

\section{Acute 5-HT2C receptor antagonism improves motor phenotypes in mice constitutively lacking the 5-HT transporter}

To test whether the effects of 5-HT2C receptor blockade can generalize from a chronic pharmacological model to a genetic one, we next examined mice in which the 5-HTT gene is ablated constitutively (5-htt-/-). 5-htt-/- mice lack 5-HTT protein throughout life and display rotarod deficits similar to those observed in mice treated chronically with FLX [2]. We treated 5-htt-/- mice and $w t$ controls acutely with either SB242084 $(5 \mathrm{mg} / \mathrm{kg}$, i.p.) or VEH and performed rotorod testing with the same parameters as in the chronic FLX cohort. In this experiment, we detected an effect of genotype and an effect of treatment at $20 \mathrm{rpm}\left(F_{1,27}=5.877, p=0.0223\right.$ and $F_{1,27}=16.734, p=0.0003$, respectively $)$ and $30 \mathrm{rpm}\left(F_{1,27}=\right.$ $15.897, p=0.0005$, and $F_{1,27}=22.025, p<0.0001$, respectively) (Fig. 1c), with acute SB242084 treatment improving the motor deficit of 5-htt-/- mice (Fig. 1c). To control for the possibility that off-target effects account for the SB242084induced rescue of motor deficits, we tested the ability of a structurally distinct 5-HT2C receptor inverse agonist, SB206553, (10 mg/kg, i.p.) to reverse motor deficits in 5-htt-/mice. We detected an effect of genotype and a genotype by treatment interaction at $20 \mathrm{rpm}\left(F_{1,26}=3.491, p=0.0073\right.$ and $F_{1,26}=4.972, p=0.0346$, respectively) and main effects for genotype and treatment at $30 \mathrm{rpm}\left(F_{1,26}=5.636, p=0.0253\right.$, and $F_{1,26}=17.17, p=0.0003$, respectively) (Fig. 1d). Posthoc analyses revealed that acute SB206553 treatment occludes the genotype effect of constitutive 5-htt ablation (Fig. 1d). These results demonstrate that acute 5-HT2C receptor blockade is sufficient to reverse the effects of 5-HTT genetic ablation on motor function, suggesting a mechanism whereby SSRIs produce motor dysfunction through increased stimulation of 5-HT2C receptors.

\section{Chronic 5-HTT blockade increases SNr neuronal activity, and 5-HT2C receptor antagonism reduces SNr neuronal activity}

5-HT2C receptors are highly expressed in non-DArgic neurons of the SNr nucleus of the BG [33-35]. SNr neurons expressing 5-HT2C are thought to mainly project to the thalamus (major BG output) and the SNc (feedback inhibition pathway) [36]. Within the $\mathrm{SNr}$, 5-HT2C receptorexpressing neurons are primarily GABAergic and are thought to inhibit SNc DAergic neurons projecting to the striatum. 5-HT applied to $\mathrm{SNr}$ neurons in slice preparations evokes an excitatory inward current that is blocked by 5 HT2C receptor antagonists [37]. Thus, excessive stimulation of 5-HT2C receptors would be expected to increase $\mathrm{SNr}$ firing and consequently increase inhibition of $\mathrm{SNc}$ DAergic neurons. We reasoned that this circuit might mediate 5-HT2C receptor-induced motor dysfunction in response to chronic FLX treatment.

To test this hypothesis, we analyzed the effect of chronic FLX treatment $(10 \mathrm{mg} / \mathrm{kg} / \mathrm{day}$, drinking water) and acute SB242084 treatment $(5 \mathrm{mg} / \mathrm{kg}$, i.p.) on the firing properties of $\mathrm{SNr}$ neurons using single-unit extracellular recordings in anesthetized mice (Fig. 2a). We detected main effects of FLX and SB242084 treatment $\left(F_{1,150}=4.349, p=0.0387\right.$ and $F_{1,150}=10.463, \quad p=0.0015$, respectively), where chronic FLX treatment increased the firing rate of $\mathrm{SNr}$ neurons, while SB242084 treatment reduced the firing rate of SNr neurons (Fig. 2b). To assess the effects of FLX and SB242084 on population activity of the SNr, we analyzed the number of spontaneously active cells per track. We found no main effect of FLX treatment, SB242084 treatment, or FLX by SB242084 interaction on the number of active cells per track $\left(F_{1,59}=0.041, p=0.8409 ; F_{1,59}=\right.$ $0.081, p=0.7773$ and $F_{1,59}=0.04, p=0.8418$, respectively) (Fig. 2c). Taken together, these data support our hypothesis that GABAergic $\mathrm{SNr}$ neuronal activity is regulated by 5 -HT2C receptors, with indirect agonism through chronic FLX increasing firing rates and 5-HT2C receptor antagonism reducing firing rates.

\section{Local infusion of 5-HT2C receptor antagonist into the SNr but not the dorsal striatum rescues motor deficits elicited by chronic 5-HTT blockade}

While the physiological signatures support the model in which 5-HT2C receptors within the $\mathrm{SNr}$ mediate the consequences of 5-HTT blockade and 5-HT2C receptor antagonism on motor behavior, these physiological and behavioral effects might be concomitant but not causally related. For example, direct effects of 5-HT2C antagonism on the striatum, where $h t r 2 c$ is expressed by cholinergic interneurons as well as medium spiny neurons of the direct and indirect pathway [38], might impact motor behavior. To test these two alternative hypotheses, we investigated if motor impairment caused by chronic 5-HTT blockade could be ameliorated by local infusion of 5-HT2C antagonist into the dorsal striatum or SNr. For this set of experiments, all mice received chronic FLX and the effect of either saline or 


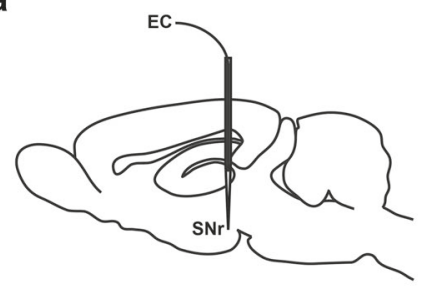

b main effect of VEH/SB242084: **

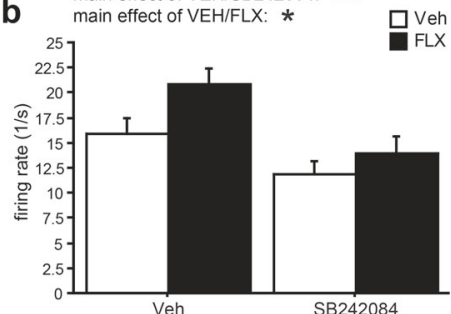

e chronic FLX

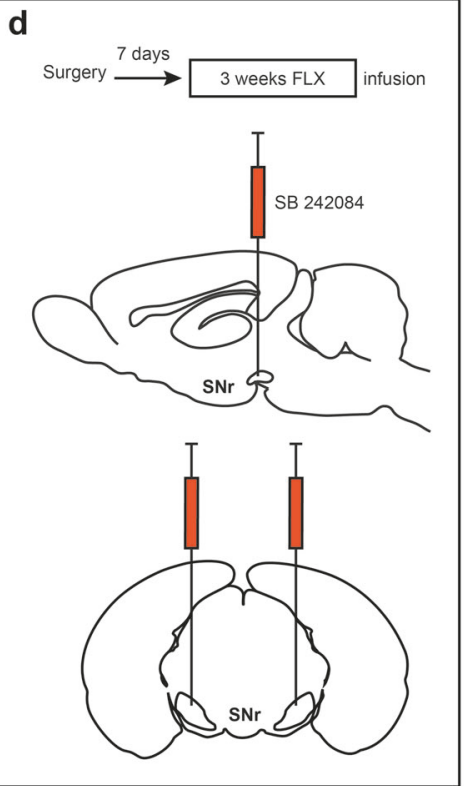

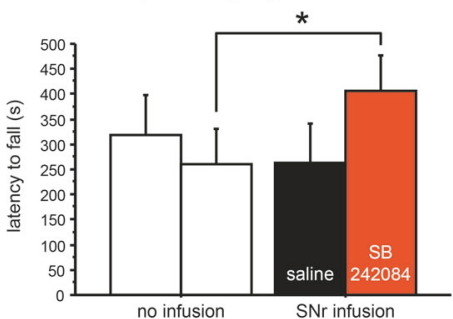

g

40 RPM, infusion by drug interaction: *

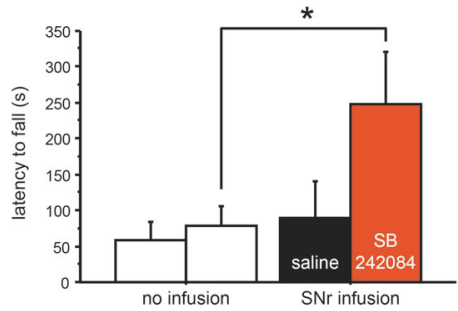

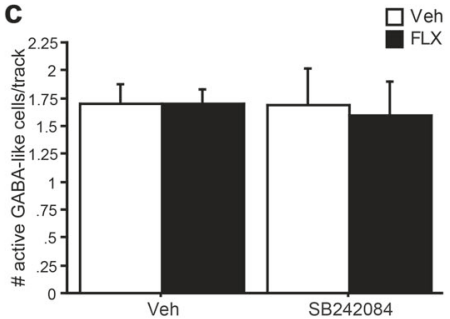
20 RPM - saline infusion

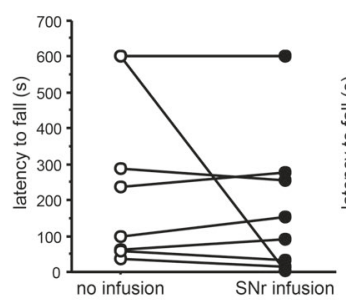

chronic FLX

20 RPM - SB242084 infusion

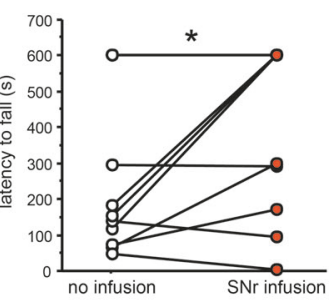

h

chronic FLX 40 RPM - saline infusion

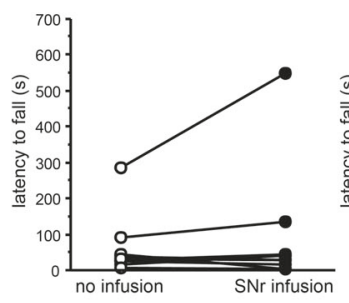

chronic FLX

40 RPM - SB242084 infusion

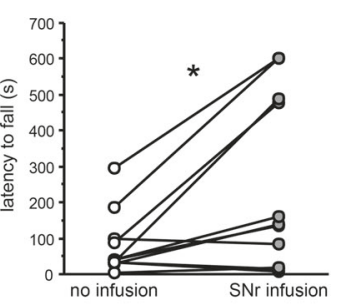

Fig. $2 \mathrm{SNr}$ 5-HT2C receptors modulate motor behavior. a Firing properties of non-DAergic SNr neurons were assessed in anesthetized mice through extracellular single unit recordings (EC). b Chronic FLX treatment $(10 \mathrm{mg} / \mathrm{kg} / \mathrm{day})$ increased and acute SB242084 treatment (5 $\mathrm{mg} / \mathrm{kg}$ ) reduced the firing rate of non-DAergic neurons within the $\mathrm{SNr}$ ( $n=30-56$ cells per group). c The amount of spontaneously active non-DAergic neurons identified per track within the $\mathrm{SNr}$ was not affected by chronic FLX or acute SB242084 treatment $(n=9-24$

SB242084 infusion was assessed (Fig. 2d, Figure S3a). We found that striatal infusions had no effect on motor performance in the rotarod test of mice chronically treated with FLX (no infusion $x$ drug interaction at $20 \mathrm{rpm}: F_{1,12}=$ $0.545, \mathrm{P}=0.4747$; no infusion $\mathrm{x}$ drug interaction at $30 \mathrm{rpm}$ : $F_{1,12}=0.002, p=0.9691$; figure S3b-e). In contrast, $\mathrm{SNr}$ infusions improved motor performance of mice chronically treated with FLX (infusion $\mathrm{x}$ drug interaction at $20 \mathrm{rpm}$ : $F_{1,19}=5.107, p=0.0358$; infusion $\mathrm{x}$ drug interaction at 40 rpm: $F_{1,19}=4.54, \quad p=0.0464 ;$ Fig. 2e-h). Therefore, antagonism of 5-HT2C receptors in the $\mathrm{SNr}$ but not the dorsal striatum, mediates the reversal of 5-HTT blockadeinduced changes in motor performance.

\section{SNr GABA neurons inhibit SNc DA neurons}

To assess the nature of the interaction between $\mathrm{SNr}$ GABAergic and SNc DAergic activity we first examined tracks per group). Motor behavior was evaluated using rotarod test (dh). d Mice cannulated in the $\mathrm{SNr}$ were treated for 3 weeks with FLX (10 mg/kg/day). e-h SB242084 (selective 5-HT2C receptor antagonist, $0.1 \mathrm{ug}$ ) acutely infused into the $\mathrm{SNr}$ increased the latency to fall at 20 $\mathrm{rpm}(\mathbf{e}, \mathbf{f})$ and at $40 \mathrm{rpm}(\mathbf{g}, \mathbf{h})$ in chronic FLX-treated animals, while local saline infusions had no effect on rotarod performance $(n=10-11$ mice per group). $(* p<0.05)$

whether direct inhibitory $\mathrm{SNr}(\mathrm{GABA})$-to-SNc(DA) projections exist. We virally expressed Cre-dependent ChR2 (AAV5-DIO-ChR2) in the $\mathrm{SNr}$ of VGAT-Cre mice, thus specifically targeting ChR2 expression to GABAergic $\mathrm{SNr}$ neurons (Fig. 3a). After 3 weeks to allow for expression, we patched SNc DAergic neurons in acute brain slices and recorded activity in response to direct stimulation of ChR2expressing $\mathrm{SNr}$ neurons (Fig. 3b). DA cells were identified based on their electrophysiological characteristics and posthoc staining for the marker tyrosine hydroxylase (Fig. 3c). We found robust inhibitory currents in SNc DA neurons in response to single pulses of blue light (Fig. 3d, e), which were blocked by bath application of gabazine (Fig. 3f, g), demonstrating that $\mathrm{GABA}_{\mathrm{A}}$ receptors mediate the inhibitory response. Next, we assessed if the $\mathrm{SNr}(\mathrm{GABA})$-to-SNc (DA) inhibitory projections exhibit characteristic properties of monosynaptic connections, namely displaying response latencies of $<10 \mathrm{~ms}$ and high reliability of evoked responses 


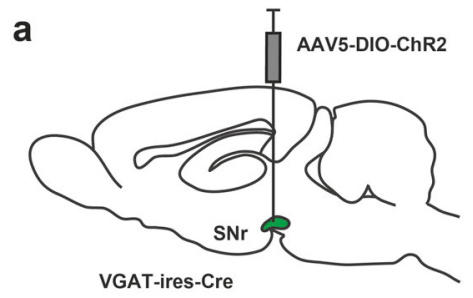

b

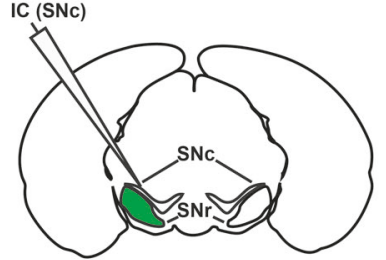

d

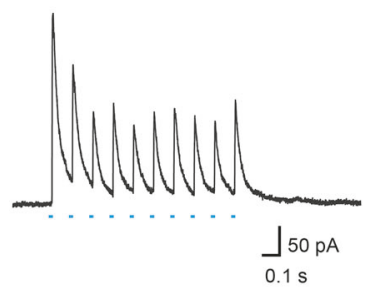

e

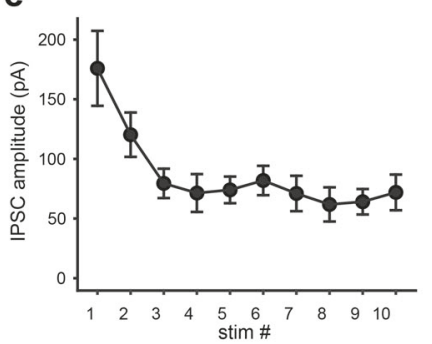

f

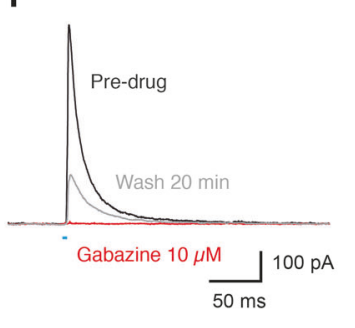

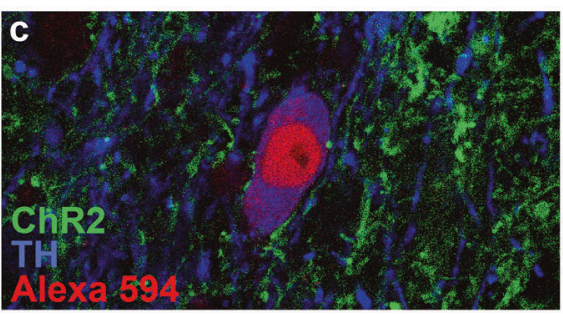

g h

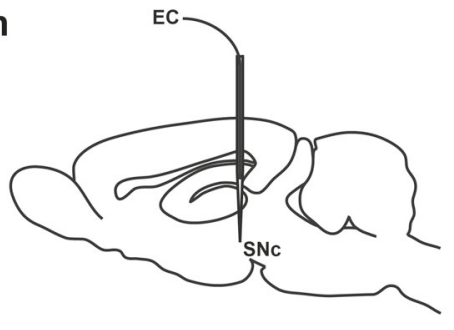

i main effect of VEH/SB242084: ***

I main effect of $\mathrm{VEH} / \mathrm{FLX}$ : $* *$

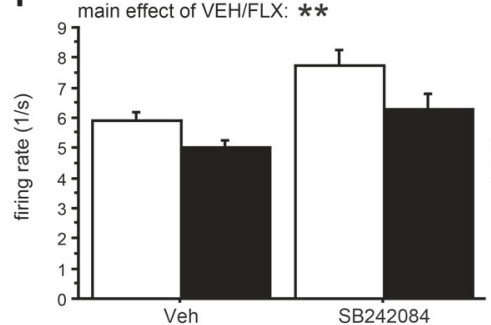

K main effect of VEH/SB242084: $* * *$

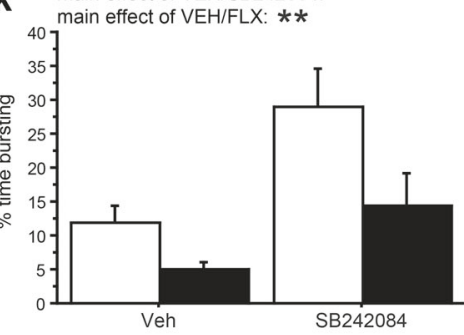

I main effect of VEH/SB242084: ***

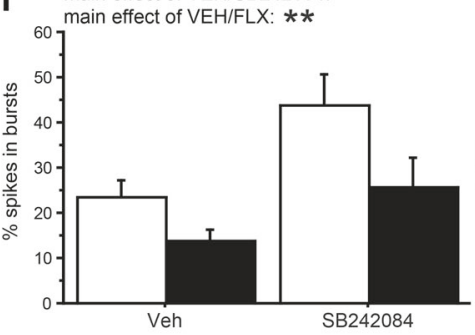

j

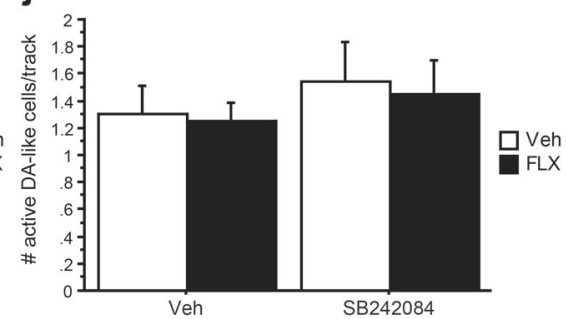

m main effect of VEH/SB242084: *

main effect of VEH/FLX: $* * *$

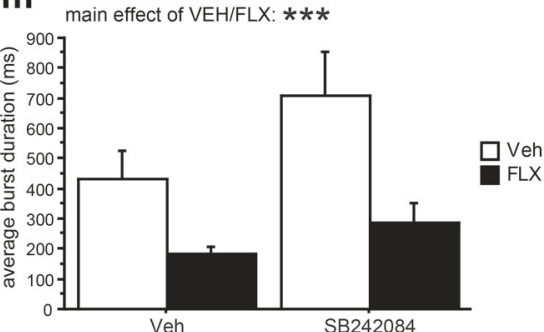

$$
40 \mathrm{mv} \frac{}{200 \mathrm{~ms}}
$$
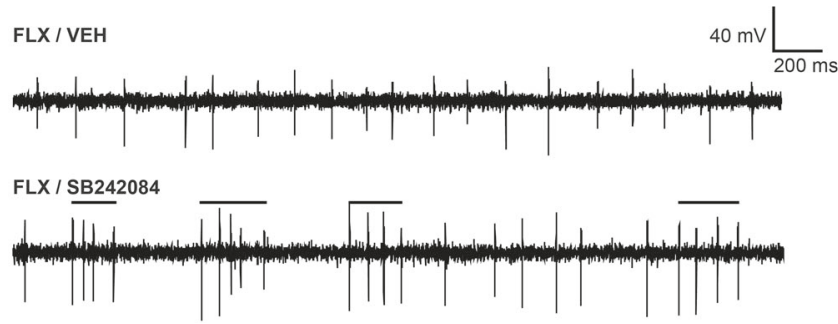

i Chronic FLX treatment (10 mg/kg/day) reduced and acute SB242084 treatment $(5 \mathrm{mg} / \mathrm{kg})$ increased the firing rate of DAergic neurons within the SNc ( $n=20-45$ cells per group). $\mathbf{j}$ The amount of spontaneously active DAergic neurons identified per track within the $\mathrm{SNc}$ was not affected by chronic FLX or acute SB242084 treatment $(n=8-$ 24 tracks per group). Chronic FLX treatment also reduced the $\%$ time bursting (k), the \% spikes per burst (l), and the average burst duration (m), while acute SB242084 treatment increased those parameters (k-m) $(n=20-45$ cells per group). n Exemplary traces with horizontal lines indicating bursts. $(* p<0.05 ; * * p<0.01 ; * * * p<0.001)$ 
with train stimulation. A non-monosynatic pathway resulting in SNr GABAergic inhibition of SNc DAergic cells would involve at least 3 synapses ( $\mathrm{SNr}(\mathrm{GABA})$ - inhibitory neuron-inhibitory neuron-SNc(DA)), which would result in a variable response to train stimulation and response latencies $>10 \mathrm{~ms}$. We find train stimulation of ChR2expressing SNr terminals in the $\mathrm{SNc}$ at $0.1 \mathrm{~Hz}$ or $10 \mathrm{~Hz}$ to reliably evoke IPSCs in DAergic with latencies of $<10 \mathrm{~ms}$ neurons thus ruling out a polysynaptic pathway (Figure $\mathrm{S} 4 \mathrm{a}-\mathrm{b})$. Together these findings demonstrate direct inhibitory $\mathrm{GABA}_{\mathrm{A}}$ receptor-mediated synaptic connections between SNr GABA and SNc DAergic neurons.

\section{Chronic 5-HTT blockade reduces SNc DAergic neuronal activity, and 5-HT2C receptor antagonism increases SNc DAergic neuronal activity}

Based on the synaptic connectivity between $\mathrm{SNr}$ GABAergic neurons and SNc DA neurons, we reasoned that if 5-HTT blockade results in increased firing of 5HT2C expressing SNr neurons, downstream DAergic neurons in the SNc would be inhibited. To test this hypothesis, we analyzed the effect of chronic FLX and acute SB242084 treatment on the firing properties of SNc DAergic neurons in anesthetized mice (Fig. 3h). Using single-unit extracellular recordings, DAergic neurons were identified using established electrophysiological criteria [26, 27]. In a subset of recordings we used Rosa-STOP-ChR2 (Ai32)+/- mice that also carry one DAT-IRES-Cre allele. These double transgenic mice (DAT::Ai32) express ChR2 in DAergic neurons [39] and we used light responsiveness to verify DAergic neuron identity and validate our electrophysiological classification criteria in the SNc (Figure S4c-f). Indeed, in these control experiments, we find that DA-like cells reliably fired in response to light stimulation with latencies $<10 \mathrm{~ms}$ (Figure S4d-f). Assessing the consequences of our pharmacologic manipulations, we found that FLX treatment $(10 \mathrm{mg} / \mathrm{kg} /$ day, drinking water) reduced the spontaneous firing rate of SNc DAergic neurons when compared to VEH-treated littermate controls, as revealed by a main effect of FLX treatment on firing rate $\left(F_{1,129}=10.415, p=0.0016\right)$. Conversely, acute SB242084 treatment $(5 \mathrm{mg} / \mathrm{kg}$, i.p.) increased the firing activity of $\mathrm{SNc}$ DAergic neurons in both FLX- and VEH-treated mice, as revealed by a main effect of SB242084 treatment on firing rate $\left(F_{1,129}=18.722, p<0.0001\right)$ (Fig. 3i). No main effect of FLX treatment, SB242084 treatment, or FLX by SB242084 interaction on the number of active DAergic cells per track were found $\left(F_{1,59}=0.128, p=0.7216 ; F_{1,59}\right.$ $=1.062, p=0.3069$, and $F_{1,59}=0.008, p=0.931$, respectively), indicating the absence of an effect on SNc DAergic population activity (Fig. 3j).
In vivo, midbrain DAergic neurons discharge with single spikes or with bursts of spikes [40]. During burst firing, neurons exhibit stereotyped bursts of 2-8 action potentials in which the first interspike interval within a burst is around 60-80 ms, followed by progressively increasing interspike intervals and progressively decreasing spike amplitudes [41]. Because burst firing leads to significantly greater DA release than single spikes [42, 43], and because bursting activity of DAergic SNc neurons is under GABAergic control [44, 45], we next analyzed the effect of chronic 5HTT blockade and acute 5-HT2C receptor antagonism on burst activity of DAergic SNc neurons. We found that the effect of chronic FLX and 5-HT2C receptor antagonism on DAergic firing rates is a consequence of altered burst firing patterns. Specifically, we detected a main effect of FLX treatment and a main effect of 5-HT2C receptor antagonism on percent time bursting $\left(F_{1,129}=10.897, p=0.0012\right.$ and $F_{1,129}=16.06, p<0.0001$, respectively) (Fig. 3k), percent of spikes that were part of burst activity $\left(F_{1,129}=9.022\right.$, $p=0.0032$ and $F_{1,129}=11.853, p=0.0008$, respectively) (Fig. 31), average burst duration $\left(F_{1,129}=15.837, p=\right.$ 0.0001 and $F_{1,129}=5.173, \quad p=0.0246$, respectively) (Fig. $3 \mathrm{~m})$, and average number of spikes per burst $\left(F_{1,129}=\right.$ 15.889, $p=0.0001$ and $F_{1,129}=7.168, \quad p=0.0084$, respectively) (Figure S5b). Chronic FLX reduced the percent time bursting, the percent of spikes per burst, the average burst duration, and the average number of spikes per burst (Fig. 3k-m, Figure S5b). Conversely, 5-HT2C receptor antagonism increased the percent time bursting, the percent of spikes per burst, the average burst duration, and the average number of spikes per burst (Fig. $3 \mathrm{k}-\mathrm{m}$, Figure S5b). No effect of FLX or SB242084 treatment or interaction of FLX and SB242084 treatment was detected for the firing rate outside of bursts $\left(F_{1,129}=3.305, p=\right.$ $0.0714 ; F_{1,129}=0.106, p=0.7449$ and $F_{1,129}=0.05, p=$ 0.8241 , respectively) (Figure $\mathrm{S} 5 \mathrm{c}$ ). In addition, no effect of FLX or SB242084 treatment or interaction of FLX and SB242084 treatment was detected for the firing rate within bursts $\left(F_{1,125}=0.664, p=0.4168 ; \quad F_{1,125}=1.242, \quad p=\right.$ 0.2672 and $F_{1,125}=0.031, p=0.8611$, respectively) (Figure S5d). Taken together, these findings demonstrate that 5 HTT-blockade impacts the balance between burst and nonburst firing of DAergic SNc neurons without affecting the firing rate within each mode (see representative traces, Fig. 3n).

In summary, these data point to a mechanism of action of 5-HTT blockade on BG output, whereby increased 5-HT levels result in activation of 5-HT2C receptor-expressing neurons within the $\mathrm{SNr}$. Increased firing of these $\mathrm{SNr}$ neurons in turn leads to enhanced inhibition of target DAergic neurons in the $\mathrm{SNc}$ as detected by the observed changes in DAergic neuron burst firing. 


\section{Optogenetic inhibition of SNc DAergic neurons produces motor deficits}

Our model posits that reduced SNc DAergic activity is causally related to motor deficits seen after chronic FLX administration. To directly test if reduced SNc DA activity is sufficient to cause motor dysfunction, we used an optogenetic approach to inhibit SNc DAergic activity and test its effects on motor function on the rotarod. We crossed RosaSTOP-Arch $(\mathrm{Ai} 35)+/+$ mice with DAT-IRES-Cre + /mice to generate double transgenic mice (DAT::Ai35) and single transgenic (Ai35+/-) control mice. Mice were trained on the rotarod without stimulation and subsequently tested for motor function with and without light stimulation $(532 \mathrm{~nm}$, continuous stimulation, $8 \mathrm{~mW})$ in a counterbalanced crossover design (Fig. 4a). We detected an interaction between genotype and light stimulation at $20 \mathrm{rpm}$ (20 rpm: $F_{1,12}=6.403, p=0.0264 ; 30 \mathrm{rpm}: F_{1,12}=2.244$, $p=0.16$ ), with posthoc analyses demonstrating significant impairment of motor performance in response to optogenetic inhibition in Arch expressing mice (Fig. 4b-e). To test for an effect of SNc DAergic inhibition on general locomotor activity, we examined mice in the open field. Indicative of preferential consequences on motor coordination, we detected only a trend effect for genotype x stimulation interaction $\left(F_{3,48}=2.514, p=0.0695\right.$; Figure S6a). These findings demonstrate that baseline SNc DAergic activity is necessary for optimal motor performance and provides support to our model that chronic 5-HTT blockade elicit motor dysfunction by inhibiting SNc DAergic activity.

\section{Optogenetic stimulation of SNc DAergic neurons reverses motor deficits elicited by chronic 5-HTT blockade}

We had previously shown that L-DOPA rescues chronic FLX-induced motor deficits [2]. Furthermore, we demonstrate that SNc DAergic inhibition evokes motor deficits. Together, these findings suggest that the motor deficits observed with chronic SSRI treatment are related to DA hypofunction. Our electrophysiological data support a model in which DA hypofunction is at least in part related to the reduction in high frequency bursting activity of DAergic neurons in the SNc. We therefore hypothesized that increasing SNc DAergic activity will counteract the decrease in bursting and potentially reverse the behavioral deficits elicited by chronic 5-HTT blockade. We tested this hypothesis by optogenetically driving DAergic neuronal activity in the $\mathrm{SNc}$ of animals during rotarod testing (Fig. 4f). We crossed Rosa-STOP-ChR2 (Ai32) +/- mice with DAT-IRES-Cre $+/$ - mice to generate double transgenic mice (DAT::Ai32) and single transgenic (Ai32 + /-) control mice. Mice were implanted with optical fibers into the SNc and trained on the rotarod without stimulation. After training, all mice were treated with FLX for 3 weeks $(10 \mathrm{mg} / \mathrm{kg} /$ day, drinking water), and subsequently tested on the rotarod with and without light stimulation $(473 \mathrm{~nm}, 20$ $\mathrm{Hz}, 10 \mathrm{~ms}$ pulse duration, $8 \mathrm{~mW}$ ) in a counterbalanced crossover design. We detected an interaction between genotype and light stimulation (20 rpm: $F_{1,12}=5.870, p=$ $\left.0.0321 ; 30 \mathrm{rpm}: F_{1,12}=4.959, p=0.0459\right)$ with posthoc analyses demonstrating significant improvement of motor performance with optogenetic stimulation in ChR2 expressing mice (Fig. $4 \mathrm{~g}-\mathrm{j}$ ). To control for an effect of DAergic stimulation on general locomotor activity, we tested mice in the open field. Indicative of selective consequences on motor coordination, we did not detect a genotype $\mathrm{x}$ stimulation interaction, nor did we detect main effects on ambulatory activity (Figure S6b). Therefore, compensating for decreased bursting of DAergic neurons in the SNc by direct local stimulation can improve motor behavior in the presence of chronic 5-HTT blockade.

\section{Interplay between 5-HT2C receptor antagonism and chronic 5-HTT blockade influences anxiety-like and depression-like behaviors}

5-HT2C receptor blockade could be an effective strategy for controlling side effects of SSRIs only in so far as this strategy does not impede the therapeutic actions of SSRIs. To gain insight into the relationship between beneficial and detrimental consequences of chronic 5-HTT blockade, we next examined whether 5-HT2C receptor antagonism affects the anxiolytic and antidepressant effects of chronic FLX. To that end, we tested the effect of both drugs either alone or in combination, in a battery of tests for anxiety and depressive-like behavior; namely the novelty suppressed feeding test (NSF), the forced swim test (FST), and the learned helplessness paradigm (LH). NSF is a conflict anxiety test in which the latency to feed is sensitive to chronic but not acute antidepressant treatment, lending predictive, face, and construct validity. We found a main effect of FLX treatment $(10 \mathrm{mg} / \mathrm{kg} /$ day, i.p. $)$ and a main effect of SB242084 treatment $(1 \mathrm{mg} / \mathrm{kg}$, i.p.) on the latency to feed $\left(F_{1,24}=8.474, p=0.0077\right.$ and $F_{1,24}=5.305, p=$ 0.0302 , respectively), with both treatments reducing the latency to feed when administered alone or in combination (Fig. 5a). No effects of treatments or interactions were detected for the control measures of body weight (FLX: $F_{1,24}=2.69, \quad p=0.114 ; \quad \mathrm{SB} 242084: F_{1,24}=2.155, p=$ 0.1551 and interaction: $F_{1,24}=0.133, p=0.7185$ ) (Figure S7a) and homecage food consumption (FLX: $F_{1,24}=$ 2.9, $p=0.1015$; SB242084: $F_{1,24}=0.841, p=0.3682$ and interaction: $F_{1,24}=0.017, p=0.8969$ ) (Figure S7b). In an independent experiment using a lower dose of acute SB242084 treatment $(0.2 \mathrm{mg} / \mathrm{kg}$, i.p. $)$ we again detected a 

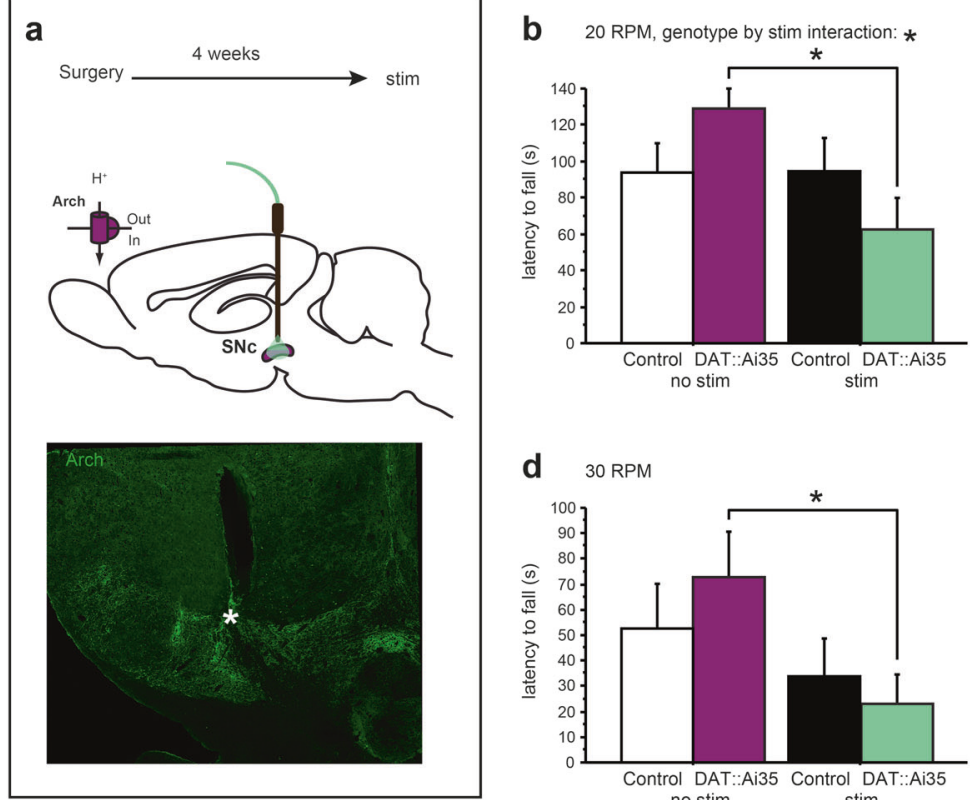

C

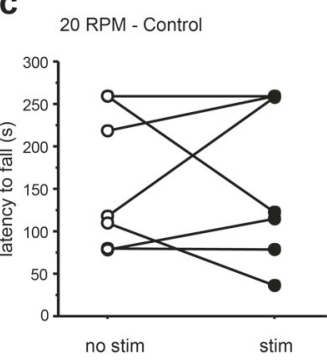

20 RPM - DAT::Ai35; SNc

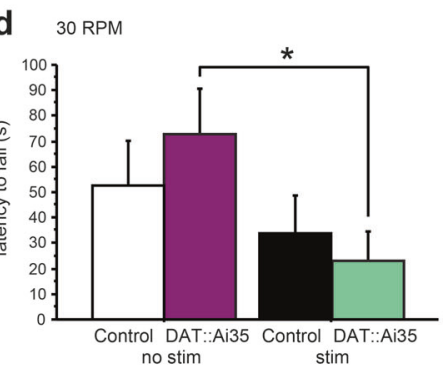

e $\quad 30 \mathrm{RPM}$ - Control
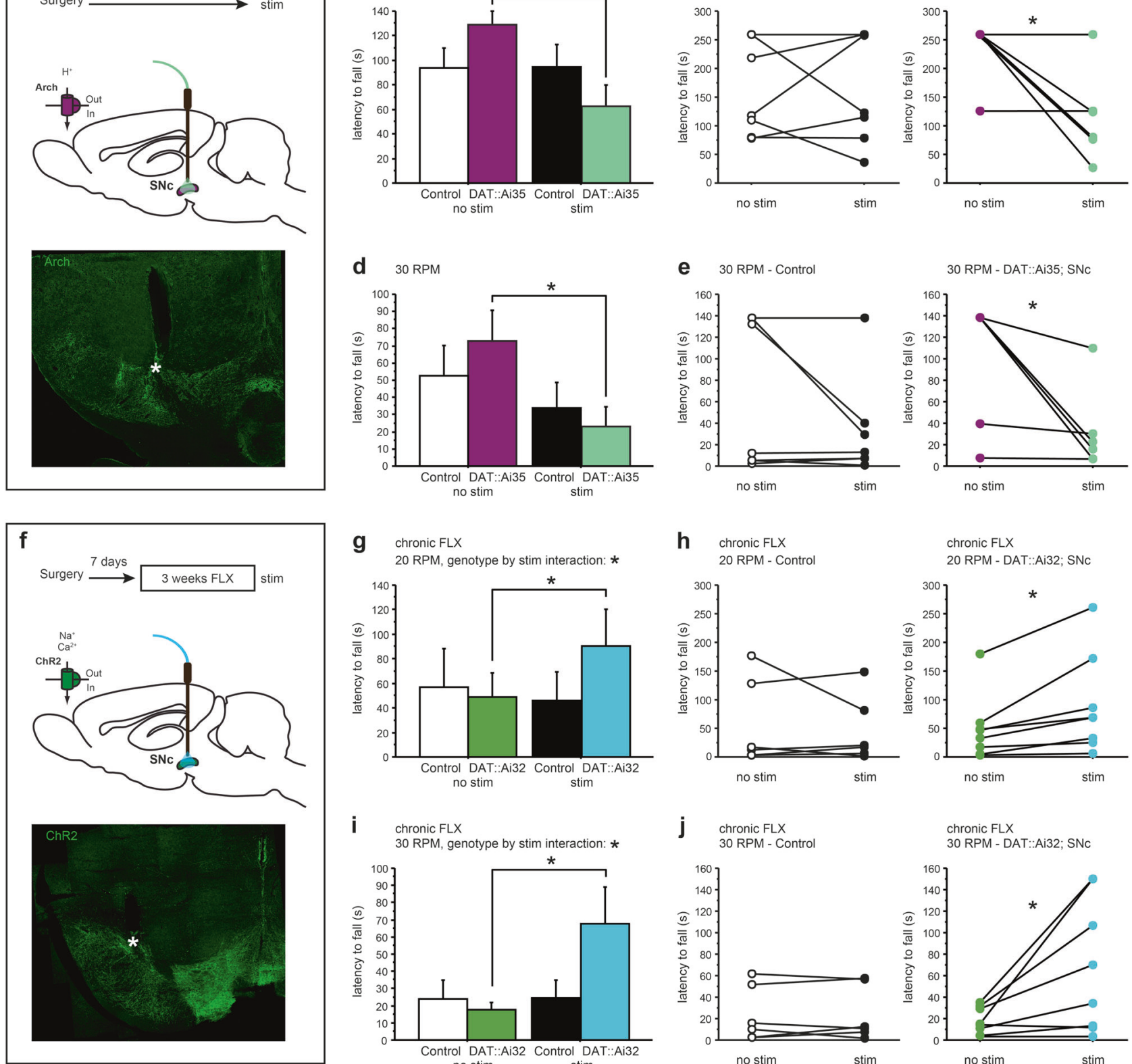

chronic FLX
20 RPM, genotype by stim interaction: *

h

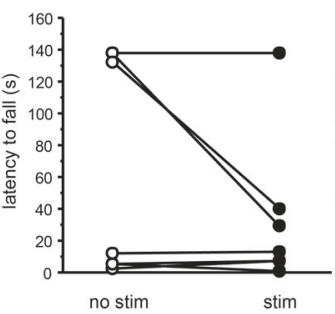

30 RPM - DAT::Ai35; SNC
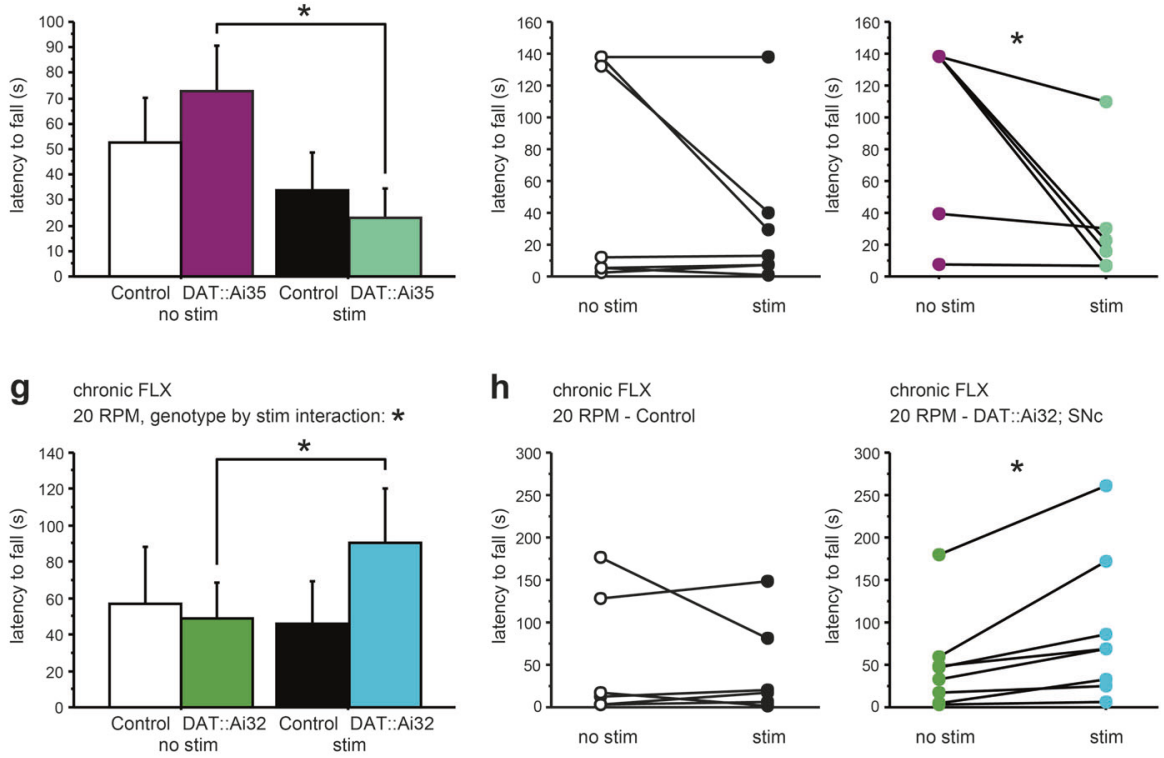

chronic FLX

20 RPM - DAT::Ai32; SNc

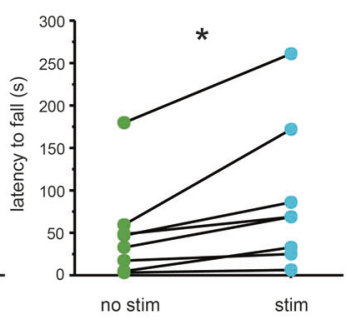

i chronic FLX

30 RPM, genotype by stim interaction: *

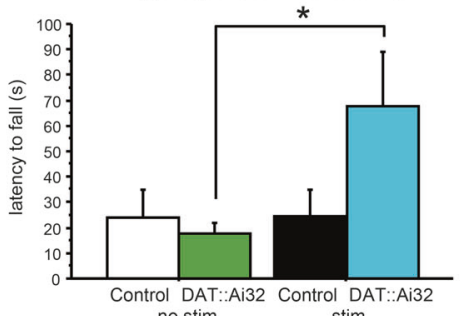

j chronic FLX

30 RPM - Control

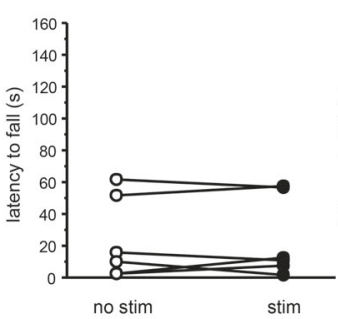

chronic FLX

30 RPM - DAT::Ai32; SNc

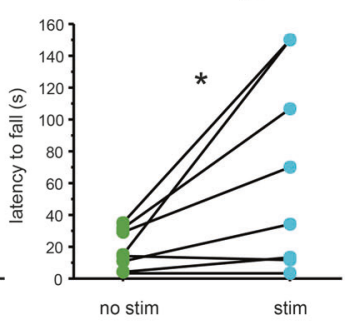

Fig. 4 Mimicry and reversal of SSRI-induced motor deficits through optogenetic modulation of SNc DAergic activity. Motor behavior was evaluated using rotarod test. a DAT-IRES-Cre::Ai35 (DAT::Ai35) or single mutant control mice were implanted bilaterally with a fiber optic cable in the SNc. b-e Optical inhibition $(532 \mathrm{~nm}$, continuous illumination, $8 \mathrm{~mW}$ ) reduced the latency to fall at $20 \mathrm{rpm}(\mathbf{b}, \mathbf{c})$ and at $30 \mathrm{rpm}$ $(\mathbf{d}-\mathbf{e})$ in DAT::Ai35 mice but not in control mice $(n=6-7$ mice per group). $(* p<0.05)$. f DAT-IRES-Cre::Ai32 (DAT::Ai32) or single mutant control mice implanted bilaterally with a fiber optic cable in the $\mathrm{SNc}$ were treated for 3 weeks with FLX $(10 \mathrm{mg} / \mathrm{kg} /$ day $)$. (g-j) Optical stimulation $(473 \mathrm{~nm}, 20 \mathrm{~Hz}, 10 \mathrm{~ms}$ pulse duration, $8 \mathrm{~mW})$ increased the latency to fall at $20 \mathrm{rpm}(\mathbf{g}, \mathbf{h})$ and at $30 \mathrm{rpm}(\mathbf{i}, \mathbf{j})$ in DAT::Ai32 mice but not in control mice ( $n=6-8$ mice per group). a, f The asterisk highlights the placement of the tip of the fiber in the tissue of a DAT::Ai35 or DAT::Ai32 mouse. $(* p<0.05)$

or in combination (Fig. 5b). Again, no effects of treatments or interactions were detected for the control measures of body weight (FLX: $F_{1,21}=1.248, p=0.2765$; SB242084: $F_{1,21}=0.006, p=0.9368$ and Interaction: $F_{1,21}=1.343, p$ $=0.2596$, respectively) (Figure $\mathrm{S} 7 \mathrm{c}$ ) and homecage food main effect of FLX treatment and a main effect of SB242084 treatment on the latency to feed in the NSF test $\left(F_{1,21}=4.395, p=0.0483\right.$ and $F_{1,21}=4.975, p=0.0367$, respectively). Post-hoc analyses revealed that both treatments reduce the latency to feed when administered alone 
Fig. 5 Chronic FLX and acute SB242084 treatment act in concert to reduce anxiety- and depression-like behaviors.

Behavior was assessed using the novelty-suppressed feeding test (a, b) and the forced swim test $(\mathbf{c}, \mathbf{d})$. The latency to feed is reduced after chronic FLX (10 $\mathrm{mg} / \mathrm{kg}$ /day) and acute SB242084 treatment at $1 \mathrm{mg} / \mathrm{kg}(n=6-8$ mice per group) (a) and $0.2 \mathrm{mg} /$ $\mathrm{kg}(n=5-8$ mice per group) (b). Mobility duration is increased after chronic FLX $(10 \mathrm{mg} / \mathrm{kg} /$ day) and acute SB242084 treatment at $1 \mathrm{mg} / \mathrm{kg}(\mathbf{c})$ and 0.2 $\mathrm{mg} / \mathrm{kg}(\mathbf{d})(n=10-12$ mice per group). (* $p<0.05 ; * * p<0.01$; $* * * p<0.001)$
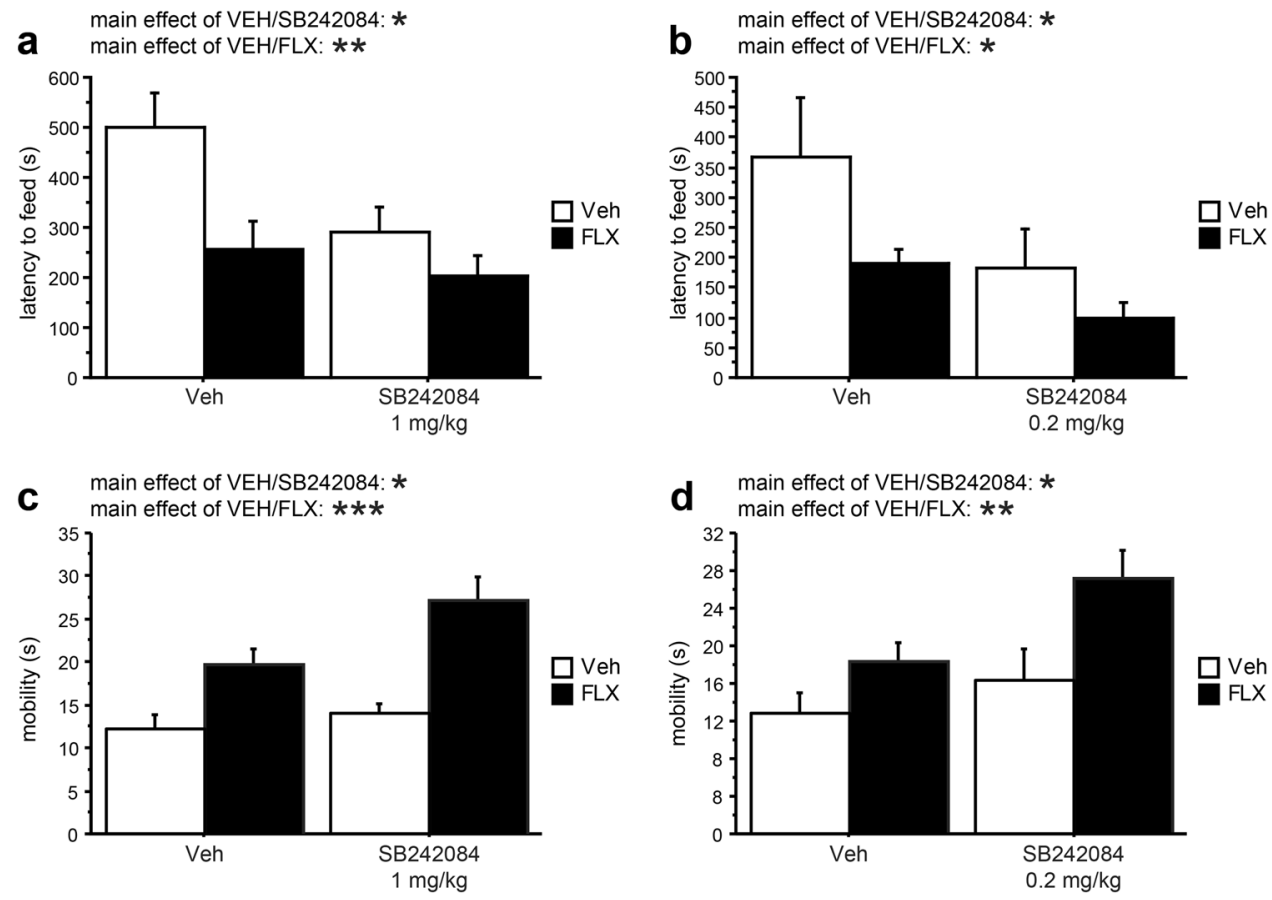

consumption (FLX: $F_{1,21}=0.277, p=0.604$; SB242084: $F_{1,21}=1.011, p=0.3262$ and interaction: $F_{1,21}=1.011, p$ $=0.3262$, respectively) (Figure $\mathrm{S} 7 \mathrm{~d}$ ). To see if acute SB242084 treatment affects general locomotor activity, we analyzed behavior in the open field test. No effect of FLX treatment (10 mg/kg/day, i.p.), SB242084 (0.2 mg/kg, i.p.), or SB242084 treatment by FLX treatment interaction was detected for total ambulatory distance $\left(F_{1,21}=2.381, p=\right.$ $0.1378 ; F_{1,21}=0.26, p=0.8741$ and $F_{1,21}=0.453, p=$ 0.5081 , respectively) (Figure $\mathrm{S} 7 \mathrm{e}, \mathrm{f}$ ).

Next, we tested the effect of chronic FLX and acute SB242084 administration on FST behavior. Following the modified FST protocol for chronic treatment [30], we first exposed mice to FST sessions over several days until mobility reached an asymptote, and then administered FLX $(10 \mathrm{mg} / \mathrm{kg} /$ day, drinking water) or $\mathrm{VEH}$ for three weeks. After the chronic treatment period mice were acutely administered SB242084 (1 mg/kg, i.p.) and re-exposed to FST. We detected a main effect of FLX treatment and a main effect of SB242084 treatment on mobility duration $\left(F_{1,44}=28.54, p<0.0001\right.$ and $F_{1,44}=5.561, p=0.0229$, respectively; Fig. 5c). Continuing chronic treatment and reassigning mice to acute treatments, we tested the effect of SB242084 at $0.5 \mathrm{mg} / \mathrm{kg}$ and $0.2 \mathrm{mg} / \mathrm{kg}$. Again, we detected main effects for FLX treatment and main effects for SB242084 treatment for mobility duration at $0.5 \mathrm{mg} / \mathrm{kg}$ $\left(F_{1,44}=40.017, p<0.0001\right.$ and $F_{1,44}=30.648, p<0.0001$, respectively; Figure $\mathrm{S} 7 \mathrm{~g})$ and $0.2 \mathrm{mg} / \mathrm{kg}\left(F_{1,44}=9.198, p=\right.$ 0.0041 and $F_{1,44}=5.126, \quad p=0.0285$, respectively; Fig. 5d). Posthoc analyses revealed additive antidepressantlike effects for all treatment combinations. Taken together, these data demonstrate that while 5-HT2C receptor antagonism reverses effects of FLX on motor function, it contributes additively to the antidepressant and anxiolytic effects of FLX.

Finally, we investigated the interaction between chronic FLX and acute SB242084 administration in a shock-based learned helplessness paradigm using a shuttle box paradigm. We chose conditions where chronic FLX alone does not have beneficial effects but instead increases the latency to escape: mice were exposed to three days of inescapable shock presentations, after which they were administered FLX $(10 \mathrm{mg} / \mathrm{kg} /$ day, drinking water $)$ or $\mathrm{VEH}$ for three weeks. On day 9 of treatment, mice were presented with mild reminder shock, and on day 21 , mice were administered SB242084 (1 mg/kg, i.p.) and behavioral responses to escapable shocks were investigated. We detected an interaction between drug treatments for escape latencies $\left(F_{1,36}=\right.$ 37.917, $p<0.0001$; Figure S8a). Posthoc analysis revealed increased latencies after FLX treatment in mice acutely administered VEH. Conversely, SB242084 treatment reduced escape latencies in mice chronically treated with either VEH or FLX. Intra-trial locomotor activity was not affected $\left(F_{1,36}=1.65, p=0.2072\right.$; Figure S8b). Therefore, 5-HT2C antagonism can rescue the adverse effects of 5HTT blockade on shock escape responses in animals subjected to learned helplessness.

In sum, not only did 5-HT2C receptor antagonism not interfere with the beneficial effects of chronic SSRI treatment but it actually further increased all of the beneficial effects that we studied independently of changing motor performance. Together our behavioral and pharmacological 
interaction studies point to 5 -HT2C receptor antagonism as an alternative or adjunct therapy for SSRI-based treatment of mood disorders.

\section{Discussion}

Understanding the mechanisms by which chronic SSRI exposure impacts DAergic circuitry to alter behavior is critical to identifying targets that can improve SSRI benefits and reduce negative effects. Our data demonstrate that chronic 5-HTT blockade impairs BG-dependent motor performance, increases $\mathrm{SNr}$ activity, and reduces $\mathrm{SNc}$ DAergic activity. Pharmacologic and optogenetic rescue experiments point to a causal chain of events, whereby 5HTT blockade leads to elevated 5-HT2C receptor signaling in $\mathrm{SNr}$ GABAergic neurons which in turn inhibit bursting activity of SNc DAergic neurons, thereby impairing motor function (Figure S9). Furthermore, our data strongly suggest additional benefits of 5-HT2C receptor antagonism for increasing the therapeutic effects of SSRIs on depression and anxiety. Taken together our findings in mice demonstrate that not only does 5-HT2C receptor antagonism reverse the effects of chronic 5-HTT blockade on BGdependent motor function, but it further improves the therapeutic effects of chronic 5-HTT blockade on affective behavior.

\section{5-HT2C receptor signaling and BG function}

Among the six 5-HT receptors tested, we found that only 5HT2C receptor antagonism reversed motor deficits. Because we investigated 5-HT1A, 5-HT1B, 5-HT2A, 5-HT4 receptors using constitutive knockout mice, we cannot exclude the possibility of developmental compensation rendering mice sensitive to the effects of chronic SSRI administration on motor function. Hence, we do not rule out the possibility of adult antagonism against these receptors to potentially also impact motor behavior but conclude that the 5-HT2C receptor plays a dominant role. 5-HT2C receptor antagonism also reversed the signature changes in $\mathrm{SNc}$ and $\mathrm{SNr}$ neuronal activity elicited by 5-HTT blockade. Together these data indicate that $5-\mathrm{HT} 2 \mathrm{C}$ receptor signaling in the $\mathrm{BG}$ modulates DAergic tone to regulate motor function.

This role of 5-HT2C receptor signaling in regulating nigrostriatal DAergic activity is in agreement with previous studies demonstrating that pharmacological activation of 5HT2C receptors inhibits firing rates of VTA neurons and DA release within the nucleus accumbens [15, 46-49]. While several studies had reported only modest effects on SNc DAergic neuronal activity if reported or present at all $[50,51]$, more recent in vivo approaches in awake animals revealed robust and even biased effects on the nigrostriatal pathway. For example, mice with a genetic ablation of $h t r 2 c$ exhibit a distinct increase in SNc DAergic firing rates but unchanged VTA DAergic activity when compared to WT mice [52]. Furthermore, using in vivo fast scan cyclic voltammetry and in vivo microdialysis in awake mice, 5-HT2C antagonism has recently been shown to selectively increase extracellular DA in the dorsomedial striatum but not the nucleus accumbens [53]. Together these findings are very much in line with our data demonstrating that 5-HT2C receptor engagement modulates $\mathrm{SNr}-\mathrm{SNc}$ signaling to impact motor function.

\section{Serotonergic modulation of DAergic activity}

5-HT neurons in the dorsal and median raphe nuclei densely innervate DAergic nuclei [54]. In rodents, the densest afferent 5-HT innervation is present in the $\mathrm{SNc}$ and $\mathrm{SNr}$ [55-59]. However, Rabies virus-based connectivity studies demonstrate that VTA DAergic neurons receive heavy monosynaptic 5-HTergic input, while SNc DAergic neurons receive little direct 5 -HTergic input $[60,61]$. These observations suggest that 5-HTergic modulation of SNc DAergic neurons is largely indirect, which is in line with our findings on $\mathrm{SNr}$ and $\mathrm{SNc}$ physiology.

Optogenetic studies have revealed that dorsal raphe input to the VTA activates DAergic neurons and carries a highly rewarding signal [61-63]. It is therefore surprising that 5HTT blockade has the opposite effect, reducing DAergic neuronal activity, dampening motivation and producing motor dysfunction [2, 20, 64]. One potential explanation for these contrasting effects could be that the different manipulations act on different pathways. Indeed, raphe nuclei contain many non-5-HTergic cells, including glutamatergic, GABAergic, and peptidergic neurons [65, 66]. A systematic input-output mapping study revealed that VTA DAergic and VTA GABAergic neurons receive complex glutamatergic, GABAergic, 5-HTergic and peptidergic synaptic inputs from DR neurons [67]. For optogenetic studies it is therefore critical how opsin expression and activation is restricted and confined through spatial and genetic means. For pharmacologic studies it is likewise critical where and in what quantities target proteins are located. Expression levels of Slc6a4, the gene encoding 5-HTT, vary among raphe neurons, which likely contributes to the specific effects of chronic SSRI treatment on different pathways [68]. Despite this complexity, our in vivo local infusion and optogenetic experimental results are consistent with a circuit model in which specific activation of 5-HT2C receptors on GABAergic neurons in the $\mathrm{SNr}$ leads to inhibition of DAergic neurons in the SNc (Figure S9). Taken together our findings and data from previous studies suggest that optogenetic stimulation of the DR and pharmacologic or genetic manipulations of 5-HTT function engage distinct or 
partially overlapping subsets of 5-HTergic projections to the DAergic nuclei, to produce different weights on opposing circuit elements that determine the net effect on physiology and behavior.

\section{Clinical implications}

Here we report 5-HTT blockade-induced, 5-HT2C receptormediated inhibition of DAergic neuronal activity. Furthermore, previous studies provide evidence that chronic 5-HTT blockade partially depletes vesicular DA levels through a crowding-out effect, when excess extracellular 5-HT is taken up by the dopamine transporter (DAT) into DAergic neurons [2, 69-71]. Both mechanisms reduce DA signaling and may underlie many of the efficacy and side-effect challenges faced with SSRI-based treatments [6]. While EPS are only a rare consequence of SSRI treatment in humans, they are the most direct analogue of the motor impairments and BG dysfunction studied here and previously in animal models [2,72-78]. Our data suggest that concurrent treatment with 5-HT2C receptor antagonists might ameliorate SSRI-induced EPS, and that more generally 5-HT2C receptor antagonists might be efficacious in treating movement disorders caused by diminished DA signaling. With BG function also controlling goal-directed motor function by regulating emotions, motivation, and cognition, the identified mechanisms might underlie SSRIinduced side effects such as anhedonia, reduced motivation, reduced libido, akathisia, agitation and apathy [79-82]. Previous studies have indeed demonstrated that 5-HT2C agonism reduces incentive motivation [16, 17], while antagonism increases incentive motivation [18-20, 53]. Taken together with the current study these data strongly suggest that it will be worthwhile to investigate the effects of 5-HT2C receptor antagonism in humans.

Excessive activation of BG loops is thought to be involved in a number of disorders associated with impaired inhibition of thoughts and behaviors as their main feature, such as OCD and Tourette Syndrome. Increased DAergic tone and fronto-striatal hyperactivity is thought to contribute to their pathophysiology [83]. If 5-HTergic control of underlying BG circuits follows the same principal rules found here, increased 5-HT2C receptor signaling should act to ameliorate these symptoms. Indeed, SSRIs are effectively used to treat some patients suffering from impaired behavioral inhibition. Our results suggest that 5-HT2C receptor agonism might be a more direct efficacious treatment approach. In agreement with this idea, lorcaserin, an approved 5-HT2C agonist for the treatment of obesity is currently in clinical trials for the treatment of nicotine addiction [84-86].

Lastly, we found that SSRI treatment and 5-HT2C receptor blockade independently reduced anxiety and depression-like behavior in the NSF and FST tests. This finding is in line with antidepressant behavioral effects of 5day 5-HT2C antagonist treatment in the FST, chronic mild stress paradigm and olfactory bulbectomy paradigm [87]. Importantly, this efficacy indicates that increased 5-HT2C receptor activation may limit the anxiolytic and antidepressant effects of SSRIs. By extension, 5-HT2C receptor antagonism as an adjunct to SSRI-based therapies might not only act to ameliorate SSRI-induced side effects but provide additional benefits to reducing hallmark symptoms of depression and anxiety disorders, such as lack of motivation and impaired execution of goal-directed behaviors.

To advance the feasibility of our translational hypotheses, it will be important to test the persistence of effects elicited by 5 -HT2C receptor antagonism. Behavioral studies indicate that rapid desensitization to 5-HT2C antagonism does not occur $[19,87]$. Furthermore, it will be important to evaluate pharmacodynamic and pharmacokinetic parameters for chronic 5-HT2C receptor targeted treatments, as well as assess potential side effects, such as excessive weight gain, in order to guide drug development further and improve treatment approaches for emotional, motivational and motor symptoms in psychiatric and neurological disorders.

Acknowledgements This work was supported by The Sackler Institute for Developmental Psychobiology, a Sackler Award (M.S.A.), and the National Institute of Mental Health (R01 MH099118, R01 MH068073). M.S.A., E.Y.D., D.S., E.M., D.M., N.C., C.T., D.S., H. M, J.A.G., P.B., and S.R. conceived the experiments. M.S.A., E.Y.D., D.S., E.M., D.M., N.C., C.T., D.S., A.Z., M.H., J.F., S.B., and A.C. performed the experiments. M.S.A., E.Y.D., D.S. and D.M., wrote the paper. We thank Christoph Kellendonk and Eleanor Simpson for their critical review of this manuscript. Rene Hen generously contributed several 5-HT receptor deficient mouse lines for these studies. Correspondence should be addressed to Mark S. Ansorge, New York State Psychiatric Institute, 1051 Riverside Drive, New York, NT 10032. ma2362@cumc.columbia.edu.

\section{Compliance with ethical standards}

Conflict of interest The authors declare that they have no conflict of interest.

\section{References}

1. Trivedi MH, Rush AJ, Wisniewski SR, Nierenberg AA, Warden D, Ritz L, et al. Evaluation of outcomes with citalopram for depression using measurement-based care in STAR*D: implications for clinical practice. Am J Psychiatry. 2006;163:28-40.

2. Morelli E, Moore H, Rebello TJ, Gray N, Steele K, Esposito E, et al. Chronic 5-HT transporter blockade reduces DA signaling to elicit basal ganglia dysfunction. J Neurosci. 2011;31:15742-50.

3. Cassano P, Fava M. Tolerability issues during long-term treatment with antidepressants. Ann Clin Psychiatry. 2004;16:15-25.

4. Preskorn SH, Ross R, Stanga CY Selective serotonin reuptake inhibitors. In: Preskorn SH, Feighner HP, Stanga CY, Ross R (eds). Antidepressants: past, present and future. Springer: Berlin, 2004, pp. 241-62. 
5. Settle EC Jr. Antidepressant drugs: disturbing and potentially dangerous adverse effects. J Clin Psychiatry. 1998;59(Suppl 16):25-30. discussion 40-22

6. Damsa C, Bumb A, Bianchi-Demicheli F, Vidailhet P, Sterck R, Andreoli A, et al. "Dopamine-dependent" side effects of selective serotonin reuptake inhibitors: a clinical review. J Clin Psychiatry. 2004;65:1064-8.

7. Price J, Cole V, Goodwin GM. Emotional side-effects of selective serotonin reuptake inhibitors: qualitative study. Br J Psychiatry. 2009;195:211-7.

8. Sansone RA, Sansone LA. SSRI-induced indifference. Psychiatry. 2010;7:14-18.

9. Di Matteo V, Di Giovanni G, Pierucci M, Esposito E. Serotonin control of central dopaminergic function: focus on in vivo microdialysis studies. Prog Brain Res. 2008;172:7-44.

10. Di Giovanni G, Di Matteo V, Pierucci M, Esposito E. Serotonindopamine interaction: electrophysiological evidence. Prog Brain Res. 2008;172:45-71.

11. Hawthorne JM, Caley CF. Extrapyramidal reactions associated with serotonergic antidepressants. Ann Pharmacother. 2015; 49:1136-52.

12. Papakostas GI. Managing partial response or nonresponse: switching, augmentation, and combination strategies for major depressive disorder. J Clin Psychiatry. 2009;70(Suppl 6):16-25.

13. De Deurwaerdere P, Di Giovanni G Serotonergic modulation of the activity of mesencephalic dopaminergic systems: therapeutic implications. Prog Neurobiol. 2016.

14. Chagraoui A, Thibaut F, Skiba M, Thuillez C, Bourin M. 5-HT2C receptors in psychiatric disorders: a review. Prog Neuropsychopharmacol Biol Psychiatry. 2016;66:120-35.

15. Prisco S, Esposito E. Differential effects of acute and chronic fluoxetine administration on the spontaneous activity of dopaminergic neurones in the ventral tegmental area. Br J Pharmacol. 1995;116:1923-31.

16. Grottick AJ, Fletcher PJ, Higgins GA. Studies to investigate the role of 5-HT(2C) receptors on cocaine- and food-maintained behavior. J Pharmacol Exp Ther. 2000;295:1183-91.

17. Zeeb FD, Higgins GA, Fletcher PJ. The serotonin $2 \mathrm{C}$ receptor agonist lorcaserin attenuates intracranial self-stimulation and blocks the reward-enhancing effects of nicotine. ACS Chem Neurosci. 2015;6:1231-40.

18. Simpson EH, Kellendonk C, Ward RD, Richards V, Lipatova O, Fairhurst $\mathrm{S}$, et al. Pharmacologic rescue of motivational deficit in an animal model of the negative symptoms of schizophrenia. Biol Psychiatry. 2011;69:928-35.

19. Bailey MR, Williamson C, Mezias C, Winiger V, Silver R, Balsam PD, et al. The effects of pharmacological modulation of the serotonin $2 \mathrm{C}$ receptor on goal-directed behavior in mice. Psychopharmacol (Berl). 2016;233:615-24.

20. Browne CJ, Fletcher PJ. Decreased incentive motivation following knockout or acute blockade of the serotonin transporter: role of the 5-HT2C receptor. Neuropsychopharmacology. 2016.

21. Lira A, Zhou M, Castanon N, Ansorge MS, Gordon JA, Francis $\mathrm{JH}$, et al. Altered depression-related behaviors and functional changes in the dorsal raphe nucleus of serotonin transporterdeficient mice. Biol Psychiatry. 2003;54:960-71.

22. Ramboz S, Oosting R, Amara DA, Kung HF, Blier P, Mendelsohn $\mathrm{M}$, et al. Serotonin receptor 1A knockout: an animal model of anxiety-related disorder. Proc Natl Acad Sci USA. 1998;95:14476-81.

23. Saudou F, Amara DA, Dierich A, LeMeur M, Ramboz S, Segu L, et al. Enhanced aggressive behavior in mice lacking 5-HT1B receptor. Science. 1994;265:1875-8.

24. Gonzalez-Maeso J, Yuen T, Ebersole BJ, Wurmbach E, Lira A, Zhou M, et al. Transcriptome fingerprints distinguish hallucinogenic and nonhallucinogenic 5-hydroxytryptamine $2 \mathrm{~A}$ receptor agonist effects in mouse somatosensory cortex. J Neurosci. 2003;23:8836-43.

25. Compan V, Zhou M, Grailhe R, Gazzara RA, Martin R, Gingrich $\mathrm{J}$, et al. Attenuated response to stress and novelty and hypersensitivity to seizures in 5-HT4 receptor knock-out mice. J Neurosci. 2004;24:412-9.

26. Bunney BS, Walters JR, Roth RH, Aghajanian GK. Dopaminergic neurons: effect of antipsychotic drugs and amphetamine on single cell activity. J Pharmacol Exp Ther. 1973;185:560-71.

27. Grace AA, Bunney BS. Nigral dopamine neurons: intracellular recording and identification with L-dopa injection and histofluorescence. Science. 1980;210:654-6.

28. Yu Q, Teixeira CM, Mahadevia D, Huang Y, Balsam D, Mann JJ, et al. Dopamine and serotonin signaling during two sensitive developmental periods differentially impact adult aggressive and affective behaviors in mice. Mol Psychiatry. 2014;19:688-98.

29. Ansorge MS, Zhou M, Lira A, Hen R, Gingrich JA. Early-life blockade of the 5-HT transporter alters emotional behavior in adult mice. Science. 2004;306:879-81.

30. Sun P, Wang F, Wang L, Zhang Y, Yamamoto R, Sugai T, et al. Increase in cortical pyramidal cell excitability accompanies depression-like behavior in mice: a transcranial magnetic stimulation study. J Neurosci. 2011;31:16464-72.

31. Muller JM, Morelli E, Ansorge M, Gingrich JA. Serotonin transporter deficient mice are vulnerable to escape deficits following inescapable shocks. Genes Brain Behav. 2011; 10:166-75.

32. Valentine G, Dow A, Banasr M, Pittman B, Duman R. Differential effects of chronic antidepressant treatment on shuttle box escape deficits induced by uncontrollable stress. Psychopharmacology (Berl). 2008;200:585-96.

33. Hoffman BJ, Mezey E. Distribution of serotonin 5-HT1C receptor mRNA in adult rat brain. FEBS Lett. 1989;247:453-62.

34. Mengod G, Nguyen H, Le H, Waeber C, Lubbert H, Palacios JM. The distribution and cellular localization of the serotonin $1 \mathrm{C}$ receptor mRNA in the rodent brain examined by in situ hybridization histochemistry. Comparison with receptor binding distribution. Neuroscience. 1990;35:577-91.

35. Eberle-Wang K, Mikeladze Z, Uryu K, Chesselet MF. Pattern of expression of the serotonin $2 \mathrm{C}$ receptor messenger RNA in the basal ganglia of adult rats. J Comp Neurol. 1997;384:233-47.

36. Hajos M, Greenfield SA. Synaptic connections between pars compacta and pars reticulata neurones: electrophysiological evidence for functional modules within the substantia nigra. Brain Res. 1994;660:216-24.

37. Stanford IM, Lacey MG. Differential actions of serotonin, mediated by 5 -HT1B and 5-HT2C receptors, on GABA-mediated synaptic input to rat substantia nigra pars reticulata neurons in vitro. J Neurosci. 1996;16:7566-73.

38. Ward RP, Dorsa DM. Colocalization of serotonin receptor subtypes 5-HT2A, 5-HT2C, and 5-HT6 with neuropeptides in rat striatum. J Comp Neurol. 1996;370:405-14.

39. Mingote S, Chuhma N, Kalmbach A, Thomsen GM, Wang Y, Mihali A et al. Dopamine neuron dependent behaviors mediated by glutamate cotransmission. Elife. 2017;13:6.

40. Freeman AS, Meltzer LT, Bunney BS. Firing properties of substantia nigra dopaminergic neurons in freely moving rats. Life Sci. 1985;36:1983-94.

41. Grace AA, Bunney BS. The control of firing pattern in nigral dopamine neurons: burst firing. J Neurosci. 1984;4:2877-90.

42. Cooper DC. The significance of action potential bursting in the brain reward circuit. Neurochem Int. 2002;41:333-40.

43. Venton BJ, Zhang H, Garris PA, Phillips PE, Sulzer D, Wightman RM. Real-time decoding of dopamine concentration changes in the caudate-putamen during tonic and phasic firing. J Neurochem. 2003;87:1284-95. 
44. Tepper JM, Martin LP, Anderson DR. GABAA receptor-mediated inhibition of rat substantia nigra dopaminergic neurons by pars reticulata projection neurons. J Neurosci. 1995;15:3092-103.

45. Paladini CA, Tepper JM. GABA(A) and GABA(B) antagonists differentially affect the firing pattern of substantia nigra dopaminergic neurons in vivo. Synapse. 1999;32:165-76.

46. Dremencov E, El Mansari M, Blier P. Effects of sustained serotonin reuptake inhibition on the firing of dopamine neurons in the rat ventral tegmental area. J Psychiatry Neurosci. 2009;34:223-9.

47. Prisco S, Pagannone S, Esposito E. Serotonin-dopamine interaction in the rat ventral tegmental area: an electrophysiological study in vivo. J Pharmacol Exp Ther. 1994;271:83-90.

48. Di Matteo V, Di Giovanni G, Di Mascio M, Esposito E. Selective blockade of serotonin2C/2B receptors enhances dopamine release in the rat nucleus accumbens. Neuropharmacology. 1998;37:265-72.

49. Di Giovanni G, De Deurwaerdere P, Di Mascio M, Di Matteo V, Esposito E, Spampinato U. Selective blockade of serotonin-2C/2B receptors enhances mesolimbic and mesostriatal dopaminergic function: a combined in vivo electrophysiological and microdialysis study. Neuroscience. 1999;91:587-97.

50. Di Giovanni G, Di Matteo V, Di Mascio M, Esposito E. Preferential modulation of mesolimbic vs. nigrostriatal dopaminergic function by serotonin(2C/2B) receptor agonists: a combined in vivo electrophysiological and microdialysis study. Synapse. 2000;35:53-61.

51. Di Matteo V, Di Giovanni G, Di Mascio M, Esposito E. SB 242084, a selective serotonin2C receptor antagonist, increases dopaminergic transmission in the mesolimbic system. Neuropharmacology. 1999;38:1195-205.

52. Abdallah L, Bonasera SJ, Hopf FW, O’Dell L, Giorgetti M, Jongsma $\mathrm{M}$, et al. Impact of serotonin $2 \mathrm{C}$ receptor null mutation on physiology and behavior associated with nigrostriatal dopamine pathway function. J Neurosci. 2009;29:8156-65.

53. Bailey MR, Goldman O, Bello EP, Chohan MO, Jeong N, Winiger V, et al. An interaction between serotonin receptor signaling and dopamine enhances goal-directed vigor and persistence in mice. J Neurosci. 2018;38:2149-62.

54. Michelsen KA, Schmitz C, Steinbusch HW. The dorsal raphe nucleus--from silver stainings to a role in depression. Brain Res Rev. 2007;55:329-42.

55. Dray A, Davies J, Oakley NR, Tongroach P, Vellucci S. The dorsal and medial raphe projections to the substantia nigra in the rat: electrophysiological, biochemical and behavioural observations. Brain Res. 1978;151:431-42.

56. Miller JJ, Richardson TL, Fibiger HC, McLennan H. Anatomical and electrophysiological identification of a projection from the mesencephalic raphe to the caudate-putamen in the rat. Brain Res. 1975;97:133-6.

57. Imai H, Steindler DA, Kitai ST. The organization of divergent axonal projections from the midbrain raphe nuclei in the rat. $\mathrm{J}$ Comp Neurol. 1986;243:363-80.

58. Vertes RP. A PHA-L analysis of ascending projections of the dorsal raphe nucleus in the rat. J Comp Neurol. 1991;313:643-68.

59. Moukhles H, Bosler O, Bolam JP, Vallee A, Umbriaco D, Geffard $\mathrm{M}$, et al. Quantitative and morphometric data indicate precise cellular interactions between serotonin terminals and postsynaptic targets in rat substantia nigra. Neuroscience. 1997;76:1159-71.

60. Ogawa SK, Cohen JY, Hwang D, Uchida N, Watabe-Uchida M. Organization of monosynaptic inputs to the serotonin and dopamine neuromodulatory systems. Cell Rep. 2014;8:1105-18.

61. Cohen JY. Dopamine and serotonin signals for reward across time scales. Science. 2015;350:47.

62. Liu Z, Zhou J, Li Y, Hu F, Lu Y, Ma M, et al. Dorsal raphe neurons signal reward through 5-HT and glutamate. Neuron. 2014;81:1360-74.
63. McDevitt RA, Tiran-Cappello A, Shen H, Balderas I, Britt JP, Marino RA, et al. Serotonergic versus nonserotonergic dorsal raphe projection neurons: differential participation in reward circuitry. Cell Rep. 2014;8:1857-69.

64. Sanders AC, Hussain AJ, Hen R, Zhuang X. Chronic blockade or constitutive deletion of the serotonin transporter reduces operant responding for food reward. Neuropsychopharmacology. 2007;32:2321-9.

65. Calizo LH, Akanwa A, Ma X, Pan YZ, Lemos JC, Craige C, et al. Raphe serotonin neurons are not homogenous: electrophysiological, morphological and neurochemical evidence. Neuropharmacology. 2011;61:524-43.

66. Weissbourd B, Ren J, DeLoach KE, Guenthner CJ, Miyamichi K, Luo L. Presynaptic partners of dorsal raphe serotonergic and GABAergic neurons. Neuron. 2014;83:645-62.

67. Beier KT, Steinberg EE, DeLoach KE, Xie S, Miyamichi K, Schwarz L, et al. Circuit architecture of VTA dopamine neurons revealed by systematic input-output mapping. Cell. 2015;162:622-34.

68. Okaty BW, Freret ME, Rood BD, Brust RD, Hennessy ML, deBairos D, et al. Multi-scale molecular deconstruction of the serotonin neuron system. Neuron. 2015;88:774-91.

69. Cases O, Lebrand C, Giros B, Vitalis T, De Maeyer E, Caron MG, et al. Plasma membrane transporters of serotonin, dopamine, and norepinephrine mediate serotonin accumulation in atypical locations in the developing brain of monoamine oxidase A knockouts. J Neurosci. 1998;18:6914-27.

70. Zhou FC, Lesch KP, Murphy DL. Serotonin uptake into dopamine neurons via dopamine transporters: a compensatory alternative. Brain Res. 2002;942:109-19.

71. Zhou FM, Liang Y, Salas R, Zhang L, De Biasi M, Dani JA. Corelease of dopamine and serotonin from striatal dopamine terminals. Neuron. 2005;46:65-74.

72. Arya DK. Extrapyramidal symptoms with selective serotonin reuptake inhibitors. Br J Psychiatry. 1994;165:728-33.

73. Leo RJ. Movement disorders associated with the serotonin selective reuptake inhibitors. J Clin Psychiatry. 1996;57:449-54.

74. Hedenmalm K, Guzey C, Dahl ML, Yue QY, Spigset O. Risk factors for extrapyramidal symptoms during treatment with selective serotonin reuptake inhibitors, including cytochrome P450 enzyme, and serotonin and dopamine transporter and receptor polymorphisms. J Clin Psychopharmacol. 2006;26:192-7.

75. Lane RM. SSRI-induced extrapyramidal side-effects and akathisia: implications for treatment. J Psychopharmacol. 1998;12:192214.

76. Caley CF. Extrapyramidal reactions and the selective serotoninreuptake inhibitors. Ann Pharmacother. 1997;31:1481-9.

77. Madhusoodanan S, Alexeenko L, Sanders R, Brenner R. Extrapyramidal symptoms associated with antidepressants--a review of the literature and an analysis of spontaneous reports. Ann Clin Psychiatry. 2010;22:148-56.

78. Gill HS, DeVane CL, Risch SC. Extrapyramidal symptoms associated with cyclic antidepressant treatment: a review of the literature and consolidating hypotheses. J Clin Psychopharmacol. 1997; 17:377-89.

79. Haber SN, Fudge JL, McFarland NR. Striatonigrostriatal pathways in primates form an ascending spiral from the shell to the dorsolateral striatum. J Neurosci. 2000;20:2369-82.

80. Haber SN. The primate basal ganglia: parallel and integrative networks. J Chem Neuroanat. 2003;26:317-30.

81. Haber SN, Calzavara R. The cortico-basal ganglia integrative network: the role of the thalamus. Brain Res Bull. 2009;78:69-74.

82. Middleton FA, Strick PL. Basal ganglia and cerebellar loops: motor and cognitive circuits. Brain Res Brain Res Rev. 2000;31:236-50. 
83. Marsh R, Maia TV, Peterson BS. Functional disturbances within frontostriatal circuits across multiple childhood psychopathologies. Am J Psychiatry. 2009;166:664-74.

84. Smith SR, Weissman NJ, Anderson CM, Sanchez M, Chuang E, Stubbe S, et al. Multicenter, placebo-controlled trial of lorcaserin for weight management. N Engl J Med. 2010;363:245-56.

85. Beard E, Shahab L, Cummings DM, Michie S, West R. New Pharmacological agents to aid smoking cessation and tobacco harm reduction: what has been investigated, and what is in the pipeline? CNS Drugs. 2016;30:951-83.

86. Higgins GA, Fletcher PJ. Therapeutic potential of 5-HT2C receptor agonists for addictive disorders. ACS Chem Neurosci. 2015;6:1071-88.

87. Opal MD, Klenotich SC, Morais M, Bessa J, Winkle J, Doukas D, et al. Serotonin 2C receptor antagonists induce fast-onset antidepressant effects. Mol Psychiatry. 2014;19:1106-14. 